\title{
Studies in Rheoencephalography (REG)
}

\author{
Michael Bodo \\ Naval Medical Research Center, Silver Spring, MD, USA \\ E-mail:michael.bodo@med.navy.mil
}

\begin{abstract}
This article presents an overview of rheoencephalography (REG) - electrical impedance measurements of the brain - and summarizes past and ongoing research to develop medical applications of REG for neuro-critical care and for primary prevention of stroke and cardiovascular disease. The availability of advanced electronics and computation has opened up the potential for use of REG technology as a noninvasive, continuous and inexpensive brain monitor for military and civilian applications. The clinical background information presented here introduces physiological and clinical environments where REG has potential for use in research and clinical settings.

REG studies over the past three decades have involved in vitro and in vivo groups (animal and human), including more than 1500 measurements and related electronic and computational results and practical applications. In vitro studies helped researchers understand the flow/volume relationship between Doppler ultrasound and electrical impedance signals and supported development of REG data processing methods. In animal studies, REG was used to monitor the lower limit of cerebral blood flow (CBF) autoregulation (AR) using a newly developed algorithm. These animal studies also confirmed correlations between REG and measurements of carotid flow (CF) and intracranial pressure (ICP). Human studies confirmed the applicability of REG for detecting cerebrovascular alteration, demonstrating the usefulness of REG in the field of stroke/cardio-vascular disease prevention. In these studies, REG was compared to known stroke risk factors and to results obtained using carotid ultrasound measurements. An intelligent REG system (Cerberus) has been developed for primary stroke prevention. In these studies, the biologically relevant variables of the REG signal were pulse amplitude (minimum maximum distance) and duration of the anacrotic (rising) portion of the REG pulse wave.

The principal limitation of REG for clinical application is the lack of pathological and physiological correlations. The studies presented here have initiated such inquiries, but many clinical questions about the pathophysiological background of REG remain unanswered.

These results demonstrate that REG development is a multidisciplinary subject with relevance for medicine (vascular neurology and neurosurgery intensive care); electronic engineering; mathematics, and computer science (data processing). It is hoped that information presented in this article will provide assistance to those involved in REG research, particularly in development and clinical applications.
\end{abstract}

Keywords: Rheoencephalography, carotid flow, intracranial pressure, cerebral blood flow autoregulation, neuro-monitoring, REG data processing, arteriosclerosis, expert system.

\section{Introduction}

\section{History}

The first published studies of bioimpedance measurements of brain circulation, in the late 1940s, show a trajectory similar to early measurements of heart and brain electrical activity (EKG and EEG). Early bioimpedance research began with thoracic (cardiac) measurements, which were soon followed by measurements of brain circulation. The term 'rheoencephalography' (REG) was first used by Jenkner. The original REG device was a four-electrode system, later modified to two electrodes.

Since the 1950s, REG devices were manufactured and widely used in such nations as Austria, Italy, USA, Soviet Union/Russia, Poland, Belgium, Bulgaria, Hungary, China, and Spain. Following the development and computerization of neurological diagnostics and the wide use of a variety of brain mapping methods, interest in REG declined because of uncertainty about what aspects of brain circulation REG measures. An impedance brain scanner was mentioned in a 1978 publication [1], but no impedance scanner device was reported as being manufactured or applied to clinical practice. Currently no manufacturer has registered a REG device with the U.S. Food and Drug Administration (FDA).

Studies in the early 1990s led to development of a computer-based REG system to measure cerebrovascular alteration caused by arteriosclerosis. Studies since 2000 have confirmed that REG measures $\mathrm{CBF}$ autoregulation, making it now possible to use REG technology to develop and test an inexpensive, non-invasive continuous brain monitor. Such development has recently received financial support from the U.S. Department of Defense [2].

Interest in the potential for using REG to measure brain circulation has been ongoing and continuous within the scientific community. Internet-based data search systems today trace REG literature back for decades. These articles illustrate the wide spectrum of REG research; however, a literature review is beyond the scope of this article. A search in Medline/Pubmed using the keyword 'rheoencephalography' produced 297 hits including three reviews and three free full tests; a Google search resulted in 21, 200 hits (December 27, 2009). REG is included in a recent international book-length publication [3] and is mentioned as a potential method for use in neurovascular monitoring method [4].

Since the early days of REG research, advances in the development of electronics, computation, and signal 
processing techniques make practical and feasible the reconsideration of REG as a technology useful in developing a portable, perhaps wearable monitoring device for $\mathrm{CBF}$ reactivity.

Some basic problems for use of electrical impedance measurements

The fact that the cost of electrical impedance instrumentation is relatively low has encouraged its possible application in many areas. The impedance measurement is influenced by such factors as geometry, tissue conductivity, and blood flow. This complexity makes it difficult to measure reliably an isolated physiologic parameter, which has been the principal factor limiting use of impedance measurement applications. The applications widely used in clinical medicine are apnea monitoring, thoracic impedance/cardiac output measurement and the detection of venous thrombosis. Other potential applications, such as those described here, need further studies $[3,5,6]$.

The disadvantage of REG as well as laser Doppler flowmetry for use in measuring $\mathrm{CBF}$ has been that neither measures in absolute flow units. However, here we demonstrate how to overcome this problem by comparing measurements made during control and challenge periods and by calculation of percentage changes appropriate for cerebrovascular reactivity $[7,8]$.

\section{Physical and Physiological Basics}

The U.S. Food and Drug Administration defines a rheoencephalograph as "a device used to estimate a patient's cerebral circulation (blood flow in the brain) by electrical impedance methods with direct electrical connections to the scalp or neck area" [9]. Previously, REG is referred to as impedance cephalography [10]. The inadequacy of this method for use in measuring flow has always been questioned [11].

The physical basis of the REG measurement is based on the fact that blood and cerebrospinal fluid are better conductors than the brain or other 'dry' tissue. The REG signal reflects the impedance change: during blood inflow into the cranial cavity, electrical conductivity increases and resistance decreases, as represented by increasing REG pulse amplitude. The REG pulse wave represents only a small percentage of the total electrical impedance. An identical change in electrical impedance occurs in a pulse wave generated during impedance measurements on peripheral sites (e.g. leg, arm), as described by Nyboer [12] in the parallel-column model. In measurements made on the skull, the input is the volume of the arterial pulse, and the output is a combination of venous and CSF outflow. The resulting impedance change - the REG curve - is the result of the equation - involving all factors mentioned here combined, not detailed individually. The measured pulsatile electrical impedance value offers the basis of several calculations, detailed by Jenker [13]. Influencing factors are detailed by
Moskalenko [14]. On the basis of previous data, REG is actually a reflection of volume rather than of flow [12]. This problem is addressed in the in vitro section.

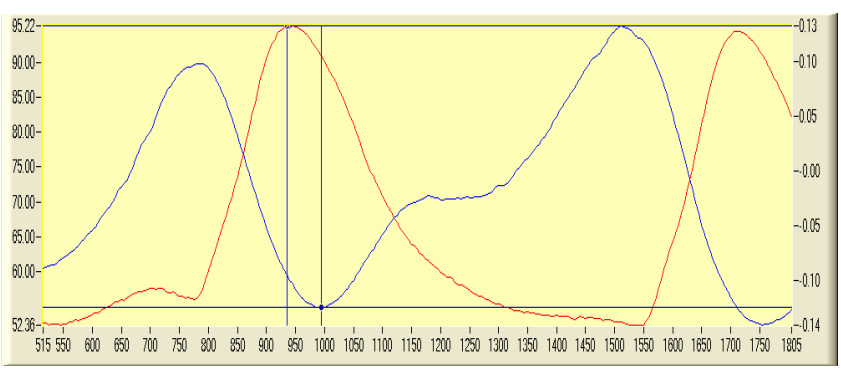

Fig.1: Arterial pressure waveform (red) REG waveform (blue). Figure illustrates the inverse relationship between the systemic arterial blood pressure (femoral artery) and the raw REG signal: impedance is decreased when tissue is filled with blood. The peak difference, indicated by two vertical bars, is about $60 \mathrm{msec}$.

\section{Medical basics}

In healthy subjects, changes in the REG pulse wave reflect heart and respiratory activity as well as brain vasoconstriction and vasodilatation. Similar pulsation can be observed in intracranial pressure (ICP) waveform. Pathological conditions in the brain typically involve changes in fluid content caused by bleeding, vascular reaction, cerebral volume changes and vessel wall hardening, which is caused by arteriosclerosis. At the same time, these changes can cause an increase in intracranial pressure and a resulting decrease in CBF. In studies of REG conducted earlier, REG was determined to be useful for detecting elevated ICP and arteriosclerosis [15]. An overview of REG can be found elsewhere [16-31], however the relationship between REG and CBF AR was missing [8,9,11,12].

Typically, Doppler ultrasound is used in clinical practice to measure CBF and cerebral hemodynamic reserve. The fact that a REG device would be much more cost effective than Doppler ultrasound or a brain mapping device such as the PET scan, explains why REG monitoring has potential for use in diagnosing cerebrovascular alterations measuring cerebral hemodynamic reserve. Brain mapping devices typically have better space resolution but worse time resolution than REG, since brain mapping devices were designed to localize brain pathology, not to monitor.

\section{REG devices used}

Studies selectively described here involve devices used in cited publications. Five types of REG devices were used (see Table 1): 1) Galileo: KR -Ea Rheo Preamp, excitation frequency of $45 \mathrm{kHz}$, time constant $3 \mathrm{~s}$ (OTE Galileo, Italy); 2) Medicor: ReoRon 61, excitation frequency of 160 $\mathrm{kHz}$ (Medicor, Hungary); 3) Cerberus: excitation frequency of $125 \mathrm{kHz}$, time constant $0.3 \mathrm{~s}$ (Quintlab, Hungary); 4) UFI: excitation frequency of $50 \mathrm{kHz}$, Model 2991 and 2994 (UFI, Inc. Morro Bay, CA); 5) MIC: Minnesota Impedance 
Cardiograph, excitation frequency of $100 \mathrm{kHz}, \mathrm{DC}-60 \mathrm{~Hz}$, model 304 B (Surcom Inc, Minneapolis, MN).

Table 1: Summary of REG studies (1975-2010) and REG devices used. Legend: Metal fragment study involved in vitro and in vivo measurements. Several hundred Cerberus measurements were excluded from this list since there was no data processing and/or Medline accessible publication. Spreading dep: depression; * Challenges were: $30 \mathrm{sec}$ breath holding, hyperventilation, $\mathrm{CO}_{2}$ inhalation, Valsalva maneuver, Trendelenburg, inverted Trendelenburg position, and Exer-Rest shaking [59].

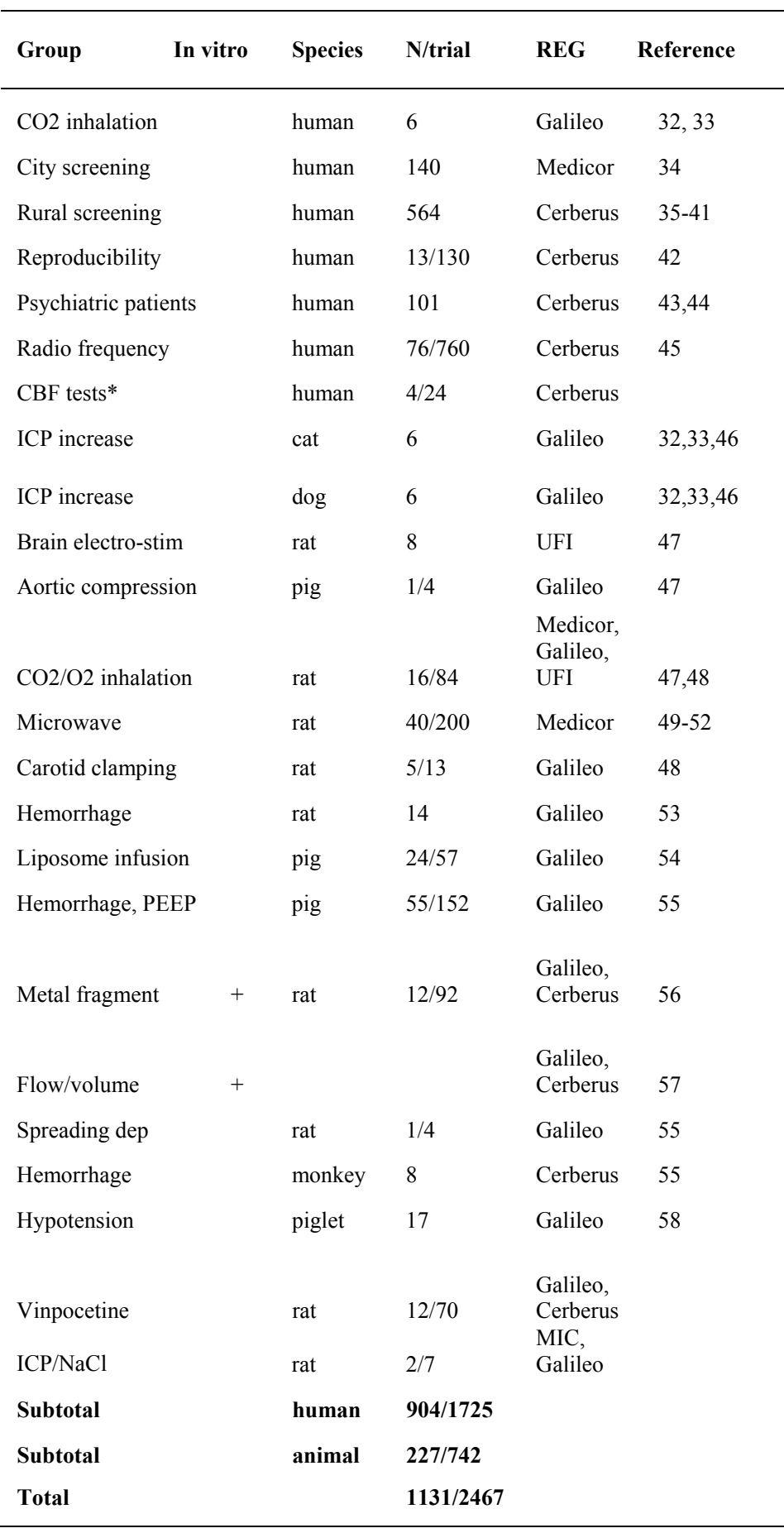

Data storage and processing

Data were sampled with $200 \mathrm{~Hz}$ analogue digital conversion rate using 1) DASH-18 (Astro-Med, West Warwick,
RI) or 2) Dell PC equipped with an analogue digital converter card with 16 bit resolution (PCI 6052E, National Instruments, Austin, TX). Data was typically processed with DataLyser. DataLyser is based upon LabVIEW software (National Instruments, Austin, TX) specifically developed in-house to record, display, store and quantify analogue physiological signals. The first step of REG processing was to remove respiration (subharmonic) in animal studies either by using the first derivative of the REG signal or using a filter. Data were exported into an Excel (Microsoft, Redmond, WA) spreadsheet for further processing unless published differently. In most cases, the Student t-test was used for statistical comparison; $p<0.05$ was considered significant.

\section{Studies}

Animal studies were performed under anesthesia; intracranial REG electrodes were normally used.

When CBF AR responses were active, they were evaluated by observing opposite directional (mirror) changes in SAP to the following: ICP, CF and REG.

Here we report together both methods and results for each study; we will not report in detail previously published studies; however, references to these studies are noted (Table 1, last column "Reference").

The study results are grouped as follows: 1) In vitro, 2) animal, 3) human.

\section{In Vitro study. Doppler and bioimpedance correlation}

One problem of REG signal interpretation is to treat it as a representation of blood volume or flow. In order to demonstrate correlation between pressure and flow, Doppler ultrasound and electrical impedance were measured in an in vitro study.

Methods: A closed loop was created using rubber and plastic tubes filled with $0.9 \% \mathrm{NaCl}$, (fig. 2). The loop involved a Doppler in-line flow probe (4N) connected to an ultrasound flow meter (T201 Ultrasonic Bloodflow Meter, Transonic Systems, Ithaca, NY); a disposable pressure transducer (Argon Medical Devices, Athens, TX) connected to a Blood Pressure Analyzer (Digi-Med, MicroMed, Louisville, KY); a peristaltic pump (Masterflex, L/S, Cole-Palmer, USA) and two stainless steel metal tubes (14 $\mathrm{mm}$ in length and $3 \mathrm{~mm}$ internal diameter) as REG electrodes of a bipolar impedance amplifier (KR-Ea RHEO Preamp, OTE Galileo, Italy). The resistance between two electrode tubes was above $10 \mathrm{ohm}$ (maximum balance). Additionally to the Doppler pulse wave, its mean flow value was stored. Baseline flow was set to $60 \mathrm{~mL} / \mathrm{min}$ and elevated flow was $120 \mathrm{~mL} / \mathrm{min}$ on the pump.

Results: The consequence of duplicating the flow resulted in an increase in pulse amplitude and mean flow of Doppler signal but not in pressure and impedance amplitudes (fig. 3.). Amplitude increase can be seen in these modalities using their first derivative (fig. 4). 


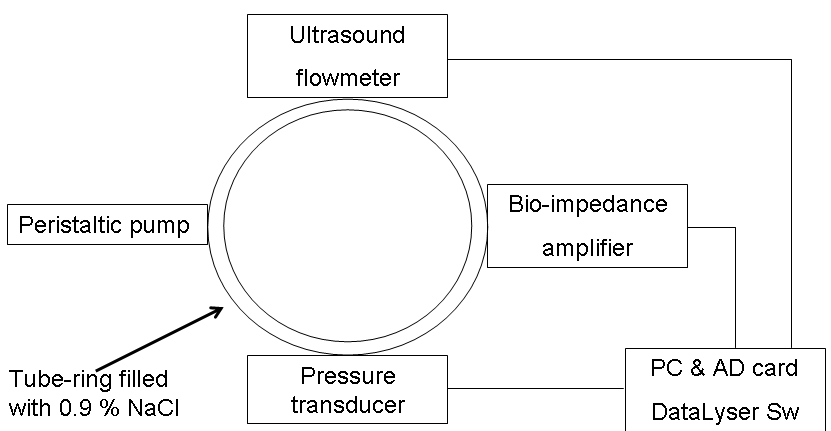

Fig.2: Block schematics of in vitro measurement: pump flow rate change caused flow change.

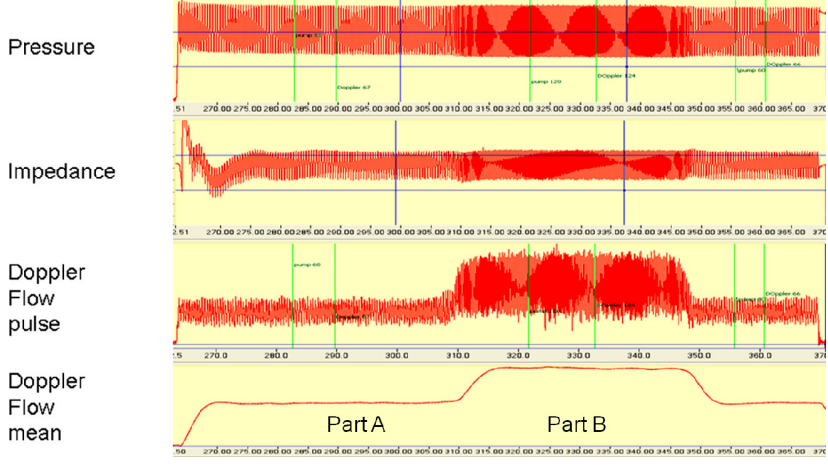

Fig.3: Traces with low pump flow (Part A) and higher flow rate (Part B). Variables in part A were: pressure: $119.57 \mathrm{mmHg}$, Mean flow: $68.08 \mathrm{~mL} / \mathrm{min}$; circulatory resistance (pressure/flow): 1.75 . Variables in part B were: pressure: $116.13 \mathrm{mmHg}$, Mean flow: $124.98 \mathrm{~mL} / \mathrm{min}$; circulatory resistance (pressure/flow): 0.93 . These variables are mean values, were calculated using 20 seconds of recording with DataLyser software, also showing traces as they can be seen with same software.

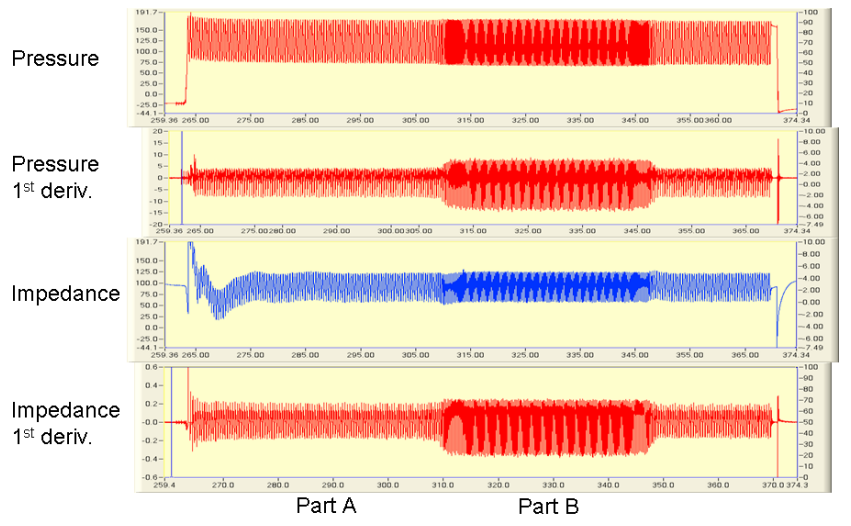

Fig.4: Traces with low pump flow (part A) and higher flow rate (part B). The first derivative of pressure and impedance showed amplitude change corresponding to increased flow (Part B).

Doubling the flow rate: 1) Affected the pulse amplitude and mean flow of the Doppler signal (increased); 2) Did not affect the amplitudes of the pressure and electrical impedance signals. However, the amplitude increase can be seen in the pressure and electrical impedance signals when the first derivatives $(\mathrm{dP} / \mathrm{dt}$ and $\mathrm{dZ} / \mathrm{dt})$ is taken.
Table 2. Comparison of Doppler flow and electrical impedance during low and high flow rates. The effects of increased flow rate were comparable between Doppler and Impedance when the impedance derivations were calculated.

\begin{tabular}{|c|c|c|c|c|c|c|c|}
\hline & & \multicolumn{3}{|c|}{ Doppler Flow } & \multicolumn{3}{c|}{ Impedance } \\
\hline & $\begin{array}{c}\text { Pump } \\
\text { Flow } \\
\text { Rate }\end{array}$ & Display & Amplitude & Mean & Amplitude & $\begin{array}{c}1^{\text {st }} \\
\text { Derivative } \\
\text { (dz.dt) }\end{array}$ & $\begin{array}{c}\text { Integral of } \\
1^{\text {st }} \\
\text { Derivative }\end{array}$ \\
\hline & $\mathrm{mL} / \mathrm{min}$ & $\mathrm{mL} / \mathrm{min}$ & $\mathrm{mL} / \mathrm{min}$ & $\mathrm{mL} / \mathrm{min}$ & $\mathrm{a} . \mathrm{u}$ & a.u. & a.u. \\
\hline mean & 60 & 67 & 68.13 & 3.58 & 2.83 & 0.09 & 0.44 \\
\hline SD & & & 17.3 & 0.005 & 1.51 & 0.05 & 0.004 \\
\hline mean & 120 & 124 & 124.98 & 4.15 & 2.83 & 0.18 & 0.91 \\
\hline SD & & & 47.9 & 0.01 & 1.54 & 0.09 & 0.003 \\
\hline ratio & 2.00 & 1.85 & 1.83 & 1.16 & 1.00 & 2.00 & 2.07 \\
\hline
\end{tabular}

\section{In-Vitro study. Effect of decreased flow}

In order to demonstrate the effect of decreased flow measured by Doppler ultrasound and electrical impedance measurements, a balloon inflation was performed inside an impedance measuring cell.

Methods: A closed loop was created using PVC and CFlex tubing filled with $0.9 \% \mathrm{NaCl}$. This loop included a Doppler in-line flow probe $(4 \mathrm{~N})$ connected to an ultrasound flow meter (T201 Ultrasonic Bloodflow Meter, Transonic Systems, Ithaca, NY). A peristaltic pump (model P720, Instech Laboratories, Plymouth Meeting, PA) generated pulse waves in the loop at a constant rate. Two stainless steel metal tubes $(14 \mathrm{~mm}$ in length and $3 \mathrm{~mm}$ internal diameter) were used as electrical impedance electrodes connected to a bipolar impedance amplifier (Cerberus). The challenge was the inflation of a balloon catheter (PTCA Dilatation catheter, NCR14 9/4.0, Boston Scientific, SCIMED, Maple Grove, MN) with a syringe in $0.5 \mathrm{cc}$ steps. Pulse amplitude measurements (minimum - maximum distance) were made at 0 (no inflation), 0.5, 1.0 and $1.5 \mathrm{cc}$ inflation. Eight pulse amplitudes were measured and averaged.

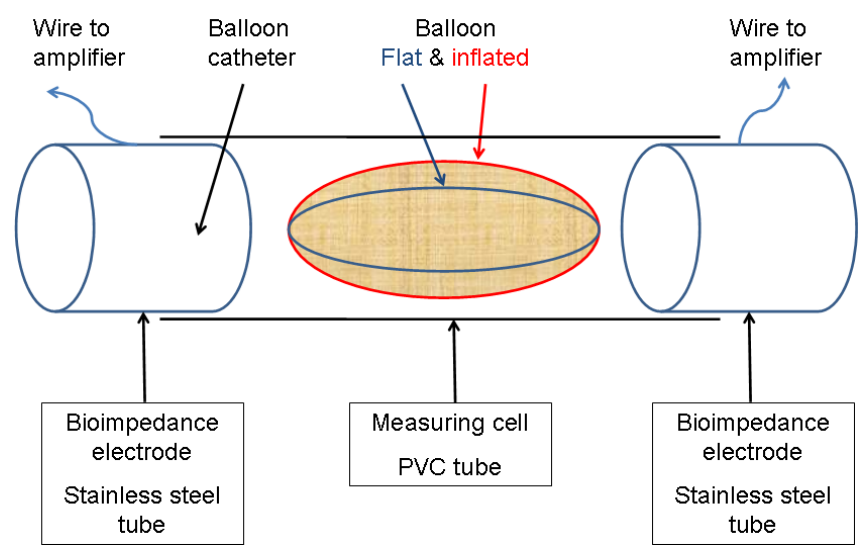

Fig.5: Impedance measuring cell for balloon inflation 


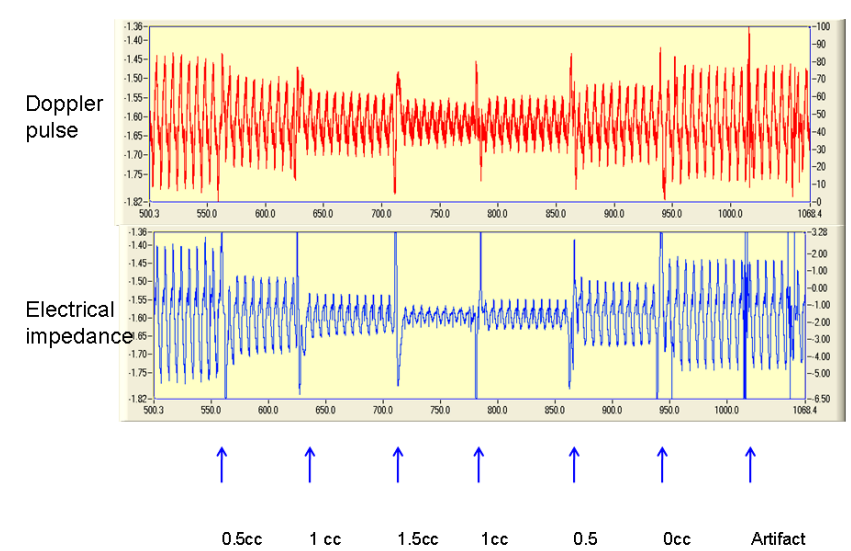

Fig.6: Effect of balloon inflation on Doppler flow and electrical impedance pulse amplitudes.

Results: 1) Balloon inflation decreased the electrical impedance pulse amplitude, identical to flow change. 2) Balloon catheter inflation elicited decreased flow. 3) Doppler and electrical impedance signals showed identical relationship to decreased flow $\left(\mathrm{R}^{2}=0.966\right)$.

\section{In Vitro study. Effect of metal fragment on bioimpedance signal}

Method: The impact of a metal fragment on the bioimpedance signal was tested [56]. The metal fragment was represented by an $18 \mathrm{~g}$ needle, placed between the bioimpedance electrodes, in a similar loop as figure 2. Temperature was measured with a temperature probe: MT-29/1 Needle microprobe (Time constant: $0.125 \mathrm{sec}$; diameter: 29 ga BAT-12 Microprobe Thermometer, Physitemp (Clifton, $\mathrm{NJ}$ ); and two home-made bioimpedance measuring cells: 1) the first was a polyethylene tube, with internal diameter of $9 \mathrm{~mm}$ and impedance electrodes were 2 stainless steel needles with diameter of $0.6 \mathrm{~mm}$, with $7 \mathrm{~mm}$ inter-electrode distance and plastic tube fittings with luer connections. 2) the second was the same polyethylene tube, with internal diameter of $9 \mathrm{~mm}$ and impedance electrodes were 2 copper metal tubes $(30 \mathrm{~mm}$ in length and $8 \mathrm{~mm}$ internal diameter) connected to a bipolar impedance amplifier (Cerberus). Inter-electrode distance (end of a copper tube to other) was $10 \mathrm{~mm}$. Metal fragments were represented by $18 \mathrm{~g}$ stainless steel needles inserted between bioimpedance electrodes half way. Doppler pulse wave and mean flow value, 2 pressure waves, temperature, 2 bioimpedance pulse waves and a voltage proportional to pump volume output were stored. For the pump, flow was set to $4 \mathrm{~L} / \mathrm{h}$. For numerical comparison, 50-second periods were measured with DataLyser; pulse wave peak amplitudes and FFT peak amplitudes were compared. Further data analysis was performed in Excel (Microsoft, Redmond, WA).

Result: The in vitro study confirmed that impedance pulses changed in the presence of metal as a function of temperature and pressure, but pulse wave amplitude did not change.

\section{In-Vitro study. REG data processing comparison}

Method: A $10 \mathrm{~Hz}$ triangle waveform, generated by a function generator (Wavetek, San Diego, CA) was stored in a PC with $200 \mathrm{~Hz}$ sampling rate with DataLyser software. The signal amplitude was changed from 1.9 to $0.4 \mathrm{~V}$ peakto-peak (pp) in 4 steps, see fig. 7. Data processing involved the calculation of various quantifications using DataLyser modules during 5 -second periods involving 1000 data points. Measured modalities were as follow: peak-to-peak amplitude in Volts (independent variable); dependent variables: standard deviation (SD), variance, root mean square (RMS), Fourier transformation peak (FFT), activity by Hjorth analysis [60] and running integral calculation. Data were entered into an Excel (Microsoft, Redmond, WA) spreadsheet and regression lines/equations were calculated.

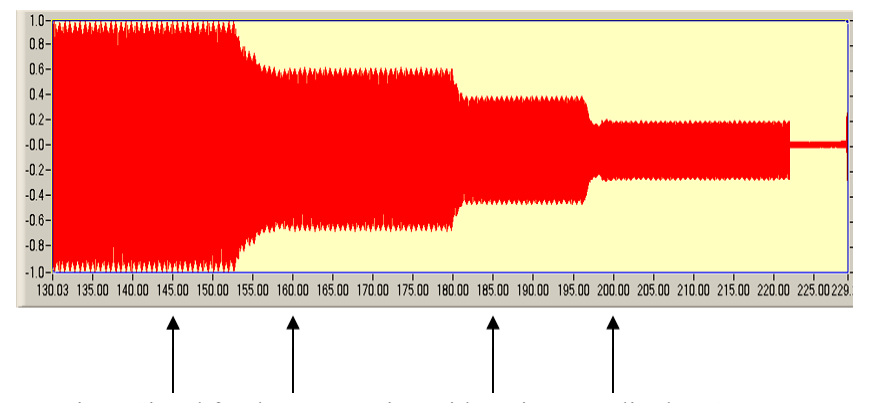

Fig.7. Signal for data processing with various amplitudes. Arrows indicate the start of processed five second signals. $Y$ axis is in Volts (left side); $\mathrm{X}$ axis is in seconds.

Results: The decrease in signal amplitude (see fig. 7) was followed by all used methods, however, the linearity was slightly different. The SD value showed the best linearity, the highest correlation coefficient, see table 2 . The running integral calculation with $5 \mathrm{~s}$ time window was unable to follow stepwise amplitude decrease, so it was left out from the comparison.

Table 2: Comparison of 5 types of data processing by their regression lines. Correlation coefficient $\left(\mathrm{R}^{2}\right)$ represents the strength of relationship between independent variable (Voltage) and dependent variables 1-5; intercept was set to 0.0 ; Hjorth A: activity, represents amplitude.

\begin{tabular}{lll}
\hline & $\mathrm{y}$ & $\mathrm{R}^{2}$ \\
\hline 1. SD & $0.3035 \mathrm{x}$ & 1 \\
2. RMS & $0.3055 \mathrm{x}$ & 0.9993 \\
3. Variance & $0.1435 \mathrm{x}$ & 0.824 \\
4. Hjorth A & $0.141 \mathrm{x}$ & 0.8093 \\
5. FFT & $0.0343 \mathrm{x}$ & 0.7847 \\
\hline
\end{tabular}




\section{Conclusion in-vitro studies}

Results of the in vitro electrical impedance studies are: 1) Modeling vasospasm/brain ischemia detected decreased pulsatile volume and flow; 2) Doppler flow and electrical impedance pulses showed identical relationship to decreased flow; 3) Electrical impedance pulse change reflected volume change. However, the increased flow resistance caused by balloon inflation also decreased flow; 4) The presence of metal did not change pulse wave amplitude; 5) SD can be used to quantify REG pulse amplitude change.

\section{Animal studies}

\section{Cat and dog}

ICP elevation was introduced by injection of artificial cerebrospinal fluid into cisterna magna. It caused transitory increase in extracellular potassium level and REG amplitudes, detailed elsewhere $[32,46]$.

\section{Rat}

In these groups studies were undertaken in anesthetized rats with intracerebral electrodes to study REG changes using standard CBF perturbations: 1) Electrical stimulation of the brain, 2) $\mathrm{CO}_{2}$ and $\mathrm{O}_{2}$ inhalation, 3) 3 - 4) $\mathrm{CO}_{2}$ inhalation, 5) carotid clamping, 6) and hemorrhage. For detailed methods and results, see [47].

\section{Electrical stimulation}

Electrical stimulation caused a REG amplitude increase in the ipsilateral (but not the contra-lateral) hemisphere. Detailed methods and results see [47].

\section{$\mathrm{CO}_{2}$ inhalation}

When $5 \% \mathrm{CO}_{2}$ was substituted for the equivalent fraction of $\mathrm{N}_{2}$ in the inspired gas mixture, there were no significant changes in the REG amplitude, indicating that this treatment was without effect on CBF. The substitution of $20 \%$ $\mathrm{CO}_{2}$ for the equivalent fraction of $\mathrm{N}_{2}$, however, markedly increased the REG signal amplitude, indicating increased CBF. During $\mathrm{CO}_{2}$ inhalation a linear relationship was established between $\mathrm{CO}_{2}$ concentration and REG peak amplitude (correlation coefficient: $0.88, \mathrm{p}=0.05$ ), and the raise time (anacrotic portion) of the curve $(0.88, \mathrm{p}=0.05)$ [31]. During $\mathrm{CO}_{2}$ inhalation increases in REG and LDF were significant, while carotid flow and systemic arterial pressure decreased. The transient increases in REG pulse amplitude $(69 \% \pm 2.6)$ and $\operatorname{LDF}(78.1 \%, 4.4)$ were highly significant $(\mathrm{p}<0.001)$ [48].

REG
Filtered
REG
Carotis L
Carotis R
SAP
$\mathrm{CO}_{2}$

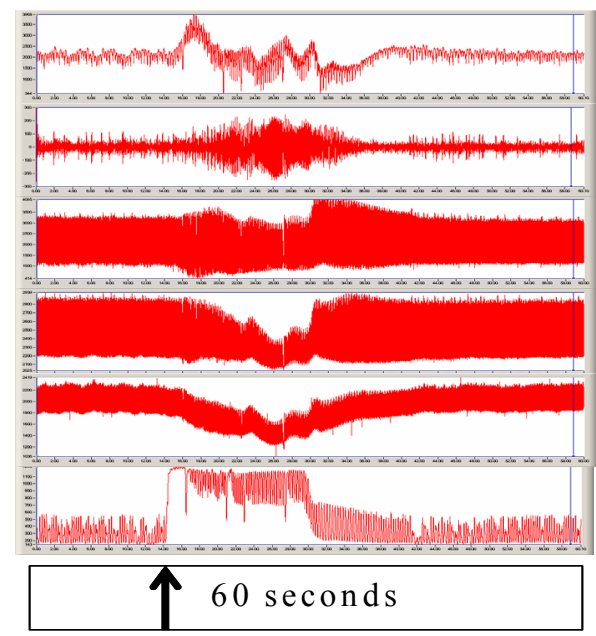

Fig.8: REG pulse amplitude increases during $\mathrm{CO}_{2}$ inhalation (subgroup A). Filtered REG: after removal of the respiratory subharmonic, Carotid L and R: left and right carotid arterial flow, SAP: systemic arterial pressure, $\mathrm{CO}_{2}$ : exhaled carbon dioxide and at the arrow: $10 \%$ inhaled $\mathrm{CO}_{2}$ during $1 \mathrm{~s}$. Time window: $60 \mathrm{~s}$. The rat/file ID was: $157-3$.

\section{Carotid clamping}

Figure 9 shows the effect of carotid artery clamping on REG amplitude and integral. During carotid artery clamping, the decrease in REG amplitude and integral were both highly significant $(\mathrm{p}<0.0001)[48]$.

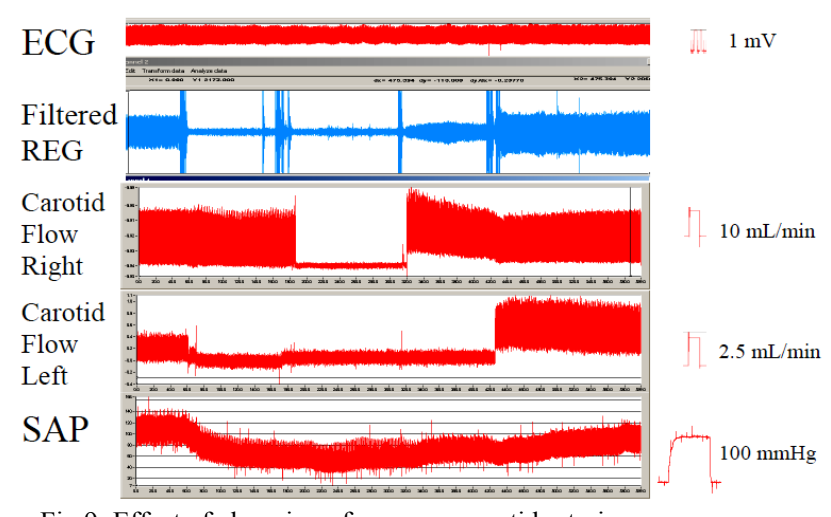

Fig.9: Effect of clamping of common carotid arteries.

Following the first clip placement on the left carotid artery, the REG amplitude (Filtered REG) decreased; the placement of the second clip on the right carotid artery gave no further decrease. During the clamping period there was no pulse amplitude observed in either carotid trace. For better visibility the recording traces were blown up; the real flow calibration values appear on the right side. Amplification of left and right carotid flow differed. A few minutes after removal of one clip from the right carotid artery, REG amplitude moderately increased, and after removal of the second clip from the left carotid artery, the REG amplitude returned to slightly above the baseline level. Similarly, both carotids showed a slight hyperemic reaction. The baseline systemic arterial pressure (SAP) value was $135 / 80 \mathrm{~mm} \mathrm{Hg}$; during clamping, the minimal value was $80 / 40 \mathrm{~mm} \mathrm{Hg}$. REG was an intra-hemispherial (left side) derivation. The 
time window was 10 min; REG Filter was 3-100 Hz. EKG: Electrocardiogram. The rat/file ID was 5-23-02/11.

\section{Hemorrhage}

During hemorrhage, REG transiently increased $(147 \% \pm$ $44 ; \mathrm{p}=0.037$ ), while cortical flow (measured by laser Doppler) $(78 \% \pm 45 ; \mathrm{p}=0.046)$ and carotid flow $(52 \pm 7.5$; $\mathrm{p}=0.005)$ decreased and correlated with systemic arterial pressure [53].

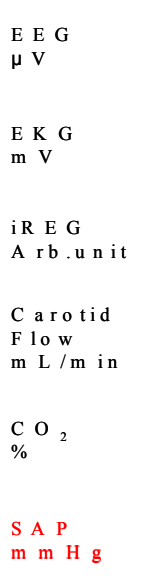

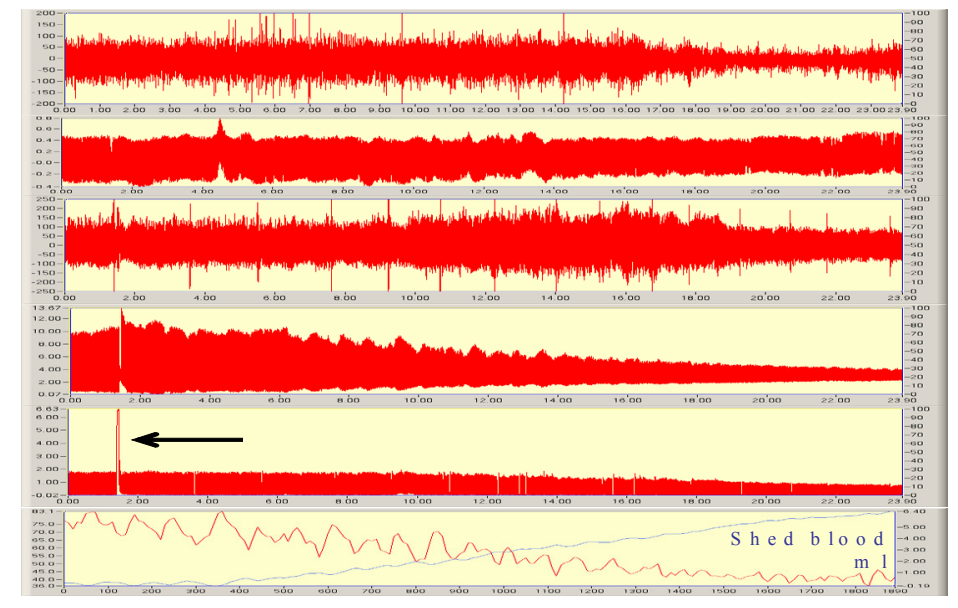

Fig.10: Increase in intracranial REG (iREG) pulse amplitude during hemorrhage. Time window: 23.9 minutes. Carotid flow decreased similarly to SAP without showing any sign of CBF AR. REG amplitude transiently increased then decreased, suggesting $\mathrm{CBF}$ AR and indicating a lower limit before $40 \mathrm{mmHg}$ SAP.

\section{Spreading depression (SD)}

In a rat study, SD and REG were measured simultaneously during ICP elevation elicited by inflating an intracerebral balloon.

DC EEG

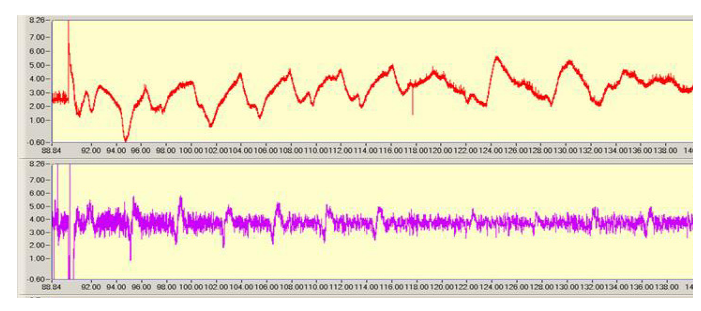

Fig.11: SD was elicited by ICP elevation. ICP elevation caused SD shown as amplitude fluctuation of DC EEG trace. REG showed close identical fluctuation.

\section{Microwave effect on CNS}

Methods: In two series of experiments on anaesthetized rats $(\mathrm{N}=40)(1)$ before and after $10 \mathrm{~min}$, whole body exposures to $2.45 \mathrm{GHz} \mathrm{CW}$ microwaves, and (2) during 30 min exposures to $4 \mathrm{GHz}$ amplitude modulated (AM, $16 \mathrm{~Hz}$ ) microwaves, the effects on the CNS were observed simultaneously with those on the cardiovascular system by quantitative polygraphic measurement. In acute experiments on rats, EEG, REG, brain tissue DC impedance and temperature and ECG were recorded simultaneously. atic Blanket Control Unit, Harvard Apparatus, Edenbridge, KT). Catheters were inserted

Results: The total power of EEG spectra increased after whole body $30 \mathrm{~mW} / \mathrm{cm}^{2} 2.45 \mathrm{GHz} \mathrm{CW}$ exposure for 10 min. No changes occurred at $10 \mathrm{~mW} / \mathrm{cm}^{2}$. The $\mathrm{CBF}$ increased after $10 \mathrm{~mW} / \mathrm{cm}^{2}$ exposure. The power of EEG delta $(0.5-4 \mathrm{~Hz})$ waves was increased by thermal level of brain localized $4 \mathrm{GHz} \mathrm{CW}$ exposure at $42 \mathrm{~mW} / \mathrm{g}$ specific absorption rate (SAR) simultaneously with the REG amplitude as an index of cerebral blood flow. Amplitude modulation at $16 \mathrm{~Hz}$ and $8.4 \mathrm{~mW} / \mathrm{g}$ SAR was associated with increased power of EEG beta $(14.5-30 \mathrm{~Hz})$ waves but changes in the $\mathrm{CBF}$ were not observed. $\mathrm{CW}$ radiation at $8.4 \mathrm{~mW} / \mathrm{g}$ increased the cerebral blood flow, but did not change EEG spectra.

\section{Metal fragments}

The impact of metal fragments on REG and EEG signals was tested.

Methods: Sprague-Dawley rats $(n=12$; weighted $463 \pm 29 \mathrm{~g}$ ) were anesthetized with sodium pentobarbital IP (50 mg/ $/ \mathrm{kg}$ ); body temperature was maintained with a heating pad-rectal thermometer system (Homeostatic Blanket Control Unit, Harinto femoral artery and trachea. The rat head was placed into a stereotaxic frame (David Kopf Instruments, Tujunga, CA). The skin was removed to expose the cranium between the sutura frontalis and the sutura lambda. The dermis, subdermal layers and periosteum over the parasagittal regions was removed.

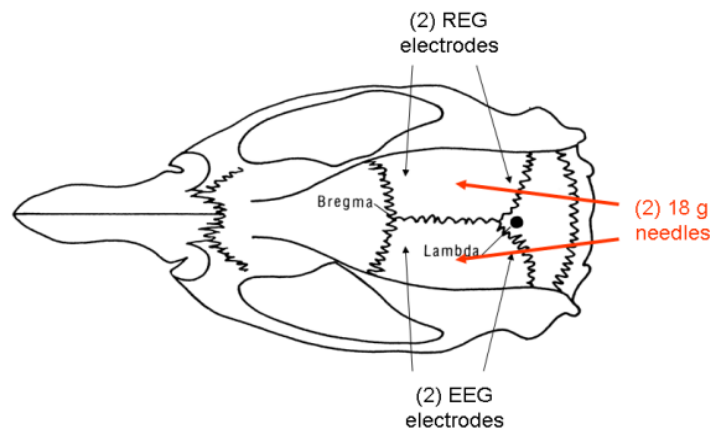

Fig.12: Dorsal view of rat skull with electrode localization.

The exposed bone was rinsed with hydrogen peroxide in preparation for the application of acrylic adhesive. Burr holes $(0.8 \mathrm{~mm})$ were drilled for both EEG (left side) and REG (right side) intracranial electrodes (E 363/1, Plastics One, Roanoke, VA) before a 2-mm distance from the sutura lambdoidea, and a 2-mm distance lateral to the sutura sagittalis. Frontal electrodes were placed $2 \mathrm{~mm}$ behind the sutura coronalis. Inter-electrode distance was $6 \mathrm{~mm}$. Burr hole was drilled between both EEG and both REG electrodes with $2.3 \mathrm{~mm}$ drill bit for a $18 \mathrm{~g}$ needle insertion (external diameter $1.3 \mathrm{~mm}$ ), fig. 12. Tests procedures were to insert and remove these needles $(n=92)$ between REG and EEG electrodes. An EEG ground was inserted into 
temporal area tissue. The electrodes were placed at a 5-mm depth, perpendicular to the surface of the skull. The diameter of all electrodes was $0.35 \mathrm{~mm}$; the length of the uninsulated electrode tips was $5 \mathrm{~mm}$. The electrodes were fixed to the skull with instant adhesive (454 Loctite, Hartford, CT); the electrodes were connected to the cables and to EEG and REG amplifiers. EEG and REG were used in intrahemispherial, bipolar derivation; the EEG amplifier used was a 7P5B Wide band EEG pre-amplifier and a 7DAG Polygraph DC driver amplifier (Grass, Quincy, MA). The setting of the filter was $0.15-35 \mathrm{~Hz}$. REG amplifier was part of Cerberus system. Systemic arterial pressure, exhaled $\mathrm{CO}_{2}$ concentration, and electrocardiogram were also recorded. REG measurement was based on its first derivative; additional measurements and calculations were made by DataLyser and Excel software.

Results: A qualitative summary of the measurement showed that 12 rats had 92 inter-electrode immersions and removals. In a few cases there was bleeding following the immersion and removal of needles (bleeding was stopped). In a subgroup of inter EEG electrode needle insertion the EEG amplitude decreased in $69 \%$ of the trials, and REG amplitude increased transiently in $92 \%$. During needle insertion between REG electrodes, EEG amplitude decreased and REG amplitude increased, both in $75 \%$ of the trials. REG reactivity persisted following placement of metal fragments in the rat brain. REG amplitude increased after placement of metal into the brain; the change was statistically non-significant.

\section{Brain impedance level}

Methods: The baseline impedance level (Z0) was measured by using $\mathrm{MIC}$ and $\mathrm{AG} / \mathrm{AgCl}$ electrodes. With stainless steel, $5 \mathrm{~mm}$ uninsulated surface electrodes, the measurement was impossible since its resistance value was above the expected range of input impedance (above $100 \mathrm{ohms}$ ) of MIC. MIC was used in two rats; outputs were $\mathrm{Z} 0, \mathrm{dZ}$, and $\mathrm{dZ} / \mathrm{dt}$. of $\mathrm{Z} 0$ and its first derivative $(\mathrm{dZ} / \mathrm{dt})$. Challenges were in MIC group: 1) inflation of Swan-Ganz catheter balloon; injection of $0.9 \% \mathrm{NaCl}$ into brain.

Results: Z0 decreased during balloon inflation and increased during saline injection with $\mathrm{AG} / \mathrm{AgCl}$ electrodes. The DZ/dt signal showed equivalent changes with ICP, see fig. 13. MIC was out of use with stainless steel electrodes because of out of range inter-electrode impedance and the automatic control: the signal had a saw-tooth shape.

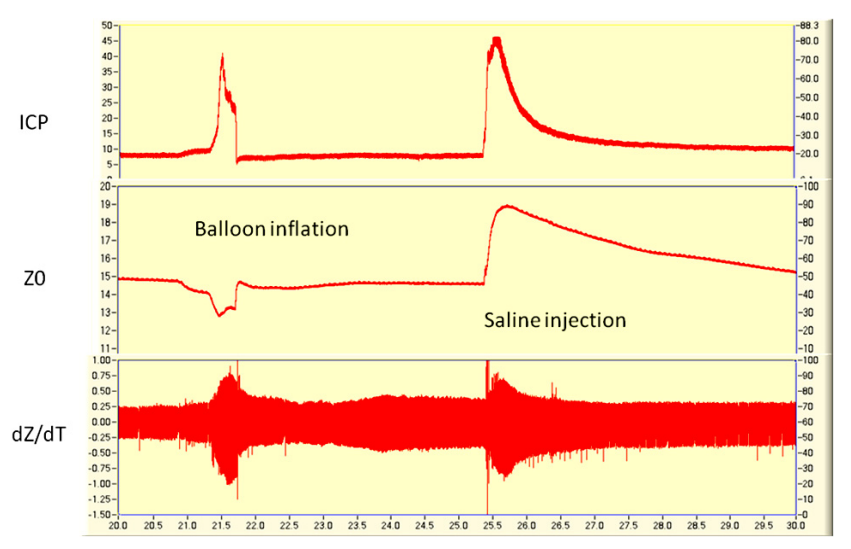

Fig.13: ICP elevation by balloon inflation and saline infusion; REG was measured by Minnesota Impedance Cardiograph. Z0 decreased during balloon inflation and increased during saline injection. REG first derivative $(\mathrm{dZ} / \mathrm{dt})$ was increased in both cases. Time window is 10 minutes. $\mathrm{dZ} / \mathrm{dt}$ was previously filtered as was described in the method section.

\section{Vinpocetine injection}

Method: Male Sprague-Dawley rats were used under Nembutal anesthesia $(50 \mathrm{mg} / \mathrm{kg})$. The surgical preparation involved 1) insertion of arterial and venous heparinized polyethylene tubing and tracheal catheters as well as 2) implantation of REG electrodes and ICP probe into the brain. REG electrodes were stainless steel intra-cerebral electrodes (Plastics One, Roanoke, VA) with $5 \mathrm{~mm}$ uninsulated surface. ICP probe was a micro sensor and the electronics was an ICP Express (Codman, Raynham, MA). REG amplifiers were Galileo and Cerberus. The challenges were: 1) iv saline infusion as control and 2) iv vinpocetine bolus infusion $(2 \mathrm{mg} / \mathrm{kg}$ ). Following the injection of vinpocetine (Cavinton, Richter Ltd, Budapest, Hungary) or control saline into the femoral vein, equivalent volume of $0.9 \%$ sodium chloride was administered to flush into the vein. Drug administration was used with 30 minutes intervals. Total number of Cavinton challenges was $70 ; n=59$ were used for statistics. Control injection $(n=36)$ involved identical volumes but without Cavinton.

Data processing: SAP and ICP mean values and REG SD were measured during 5 seconds. REG pulse amplitude measurement was performed after previous filtering (removing respiratory sub-harmonics and noise) with a 2-50 $\mathrm{Hz}$ inverted Chebyshev filter. Mean values of SAP, ICP, $\mathrm{SD}$ of $\mathrm{CF}$ and REG signals were used for statistical comparison. The control samples were taken from each modality before SAP change. The challenge samples were taken at the time of maximal response in REG and CF. To quantify and compare SAP, ICP,CF and REG changes, the formula of cerebrovascular vasomotor reactivity calculation was used [7,8].

Results: Intravenous injection of vinpocetine, measured by two bipolar REG systems, showed that a vinpocetine bolus caused a transient decrease in SAP and simultaneous increase in ICP and REG pulse amplitude. During control volume injection there was no blood pressure decrease and consequent vasodilatation response in ICP and REG. 


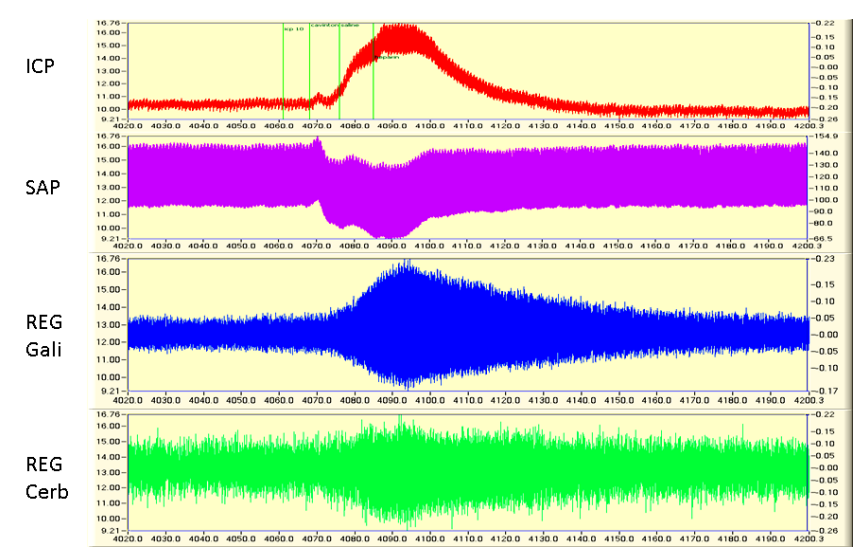

Fig.14: Typical changes during vinpocetine bolus injection: SAP decreased, ICP elevated and REG pulse amplitudes increased. REG was filtered as described in methods session. Time window: 180 seconds. File: 2009 Oct 2 -2 (4020-4200 s)

The average response to vinpocetine bolus injection was as follows: SAP decrease was $25.21 \pm 14.41 \%$; ICP increase was $27.86 \pm 15.82 \%$; REG pulse amplitude increase was (Galileo) $209.44 \pm 166.26 \%$ and (Cerberus) $106.93 \pm$ $68.40 \%$.

\section{Pig studies}

In these groups studies were undertaken REG changes using standard CBF perturbations: 1) aortic compression, 2) PEEP, 3) hemorrhage, 4) liposome injection.

\section{$\underline{\text { Aortic compression }}$}

During aortic occlusion (caused by abdominal compression) the systemic arterial blood pressure increased $59.67+$ $11.92 \%$ (mean $+\mathrm{SD} ; \mathrm{p}=0.008)$, LDF increase was nonsignificant $10.75+2.21 \%$ (mean $+\mathrm{SD} ; \mathrm{p}=0.089)$, and REG decreased $23.75+8.18 \%$ (mean $+\mathrm{SD} ; \mathrm{p}=0.01)$; for details see [47].

\section{Hemorrhage and PEEP}

Methods: CBF AR responses of 55 anesthetized Yorkshire pigs and 150 trials were evaluated during several $\mathrm{CBF}$ manipulations: haemorrhage, positive end-expiratory pressure (PEEP), and transitory SAP decrease and increase. Pigs were anesthetized with isoflurane and propofol/ketamin anaesthesia. The animals were monitored both with a bispectral index (BIS) device (A-2000, Aspect Medical Systems, Newton, MA) and with an anaesthesia monitor (isoflurane, $\mathrm{O}_{2}, \mathrm{CO}_{2}$ ) with RGM 5250 (Datex Ohmeda, Louisville, CO). SAP was measured with a Microtip disposable pressure transducer inserted into the femoral artery, with a transducer control unit (Millar Instruments, Houston, TX), and with a Digi-Med Blood Pressure Analyzer, (Micro-Med, Louisville, KY). CF was measured on the right carotid artery with T201 ultrasonic blood flow meter (Transonic Systems, Ithaca, NY). REG was measured with a KR-Ea RHEO Preamp $(45 \mathrm{kHz}$; Galileo, Italy), a bipolar system. Two electrodes were made from stainless steel (40 $\mathrm{mm}$ in length) and implanted into the brain via a burred hole (about $10 \mathrm{~mm}$ parasagittaly on the right side; inter-electrode distance of 10-20 mm) above and below the fronto-parietal sutura. Electrodes were fixed to the skull with Vetbond tissue adhesive (3M, St. Paul, $\mathrm{MN}$ ) and instant adhesive 454 (Loctite, Hartford, CT). Average inter-electrode resistance was $1.9 \mathrm{ohm}+/-0.55$ (n $=25$ ). $\mathrm{CBF}$ AR was evaluated first by visual inspection of traces to establish the presence of CBF AR. In the PEEP and $\mathrm{CBF}$ groups, 13-13 pigs were measured. In the COMP group ("complement activation"), 33 pigs were measured; a few were excluded because of missing CF, REG or artefactcontaminated recordings; some recordings offered more than one $\mathrm{CBF}$ AR response.

Data processing involved measurement of 30 second traces (6000 data points) of SAP, CF and REG using DataLyser. In the PEEP group, REG was filtered with 0.5 - 100 $\mathrm{Hz}$, Butterworth, 512 points, order: 5, attenuation: $40 \mathrm{~dB}$. Additionally, REG first derivative was used, negative values were converted to positive, and integrated.

Mean values of SAP, standard deviation of CF and REG signals were used for statistical comparison. The control samples were taken from each modality before SAP change. The CBF AR sample was taken at the time of maximal response in REG and CF. Percentage change between control and CBF AR maximum was used to compare SAP, CF and REG to each other.
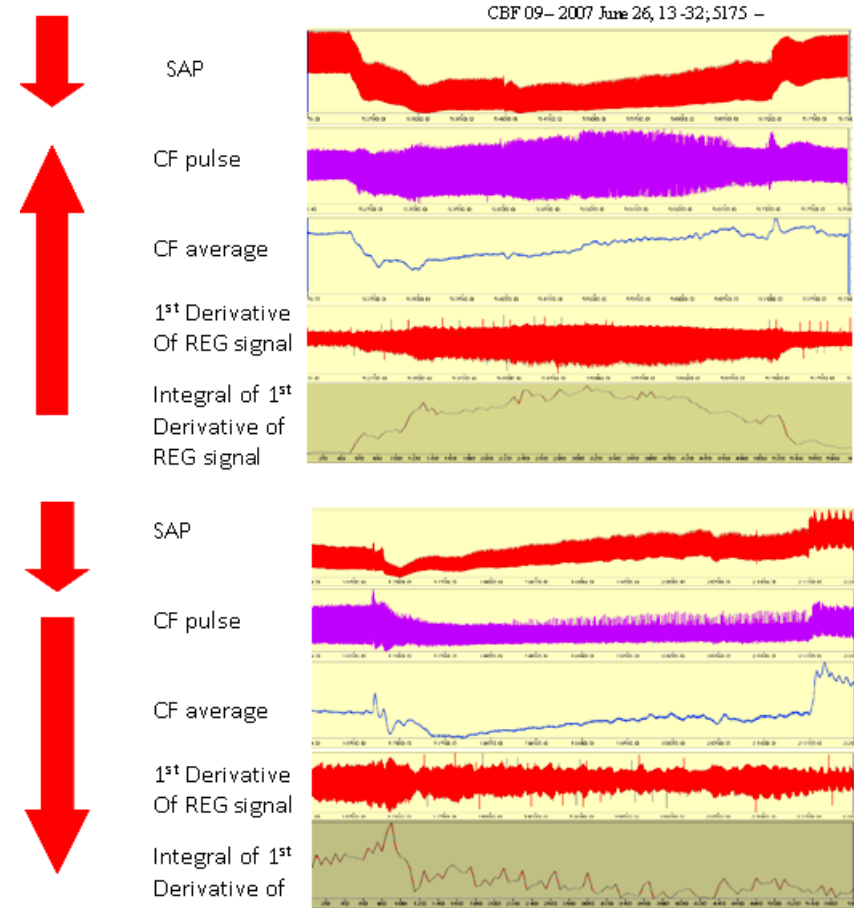

REG signa

Fig.15: Comparison of CBF AR: Effect of $20 \mathrm{~cm} \mathrm{H}_{2} 0$ PEEP before and after hemorrhage. Before hemorrhage (upper panel); Hemodynamic status: SAP 120/78; mean $92 \mathrm{mmHg}$; CBF AR present since SAP decrease elicited increase in CF and REG pulse amplitudes. After hemorrhage (lower panel; blood loss of $\sim 1.3 \mathrm{~L}$ with estimated SBV of $30 \%$ ); hemodynamic status: SAP 90/67; mean $75 \mathrm{mmHg}$. CBF AR impaired since SAP decrease elicited decrease in CF and REG pulse amplitudes. 
Results: CBF AR responses were observed during PEEP, hemorrhage and transitory SAP changes. In CBF group mean SAP values for losing CBF AR by REG and CF were $47.88 \pm 8.26$ and $49.48 \pm 7.28 \mathrm{mmHg}$; the difference was not significant. Hemorrhage elicited a decrease in SAP and transitory increases in REG and CF amplitude; 2) PEEP resulted in a decrease in SAP and increases in REG and CF amplitude; 3) PEEP after hemorrhage caused decreases in SAP, REG and CF amplitudes. When CBF AR was present, it was detected by both REG and CF. Following hemorrhage, $\mathrm{CBF}$ AR was lost; CF and REG passively followed SAP. Additional observation is that PEEP can be used to test CBF AR.

Results of statistical analysis (PEEP group); REG and carotid flow: a strong linear relationship (Pearson's correlation $=-0.92$ ) was established, fig. 16 .

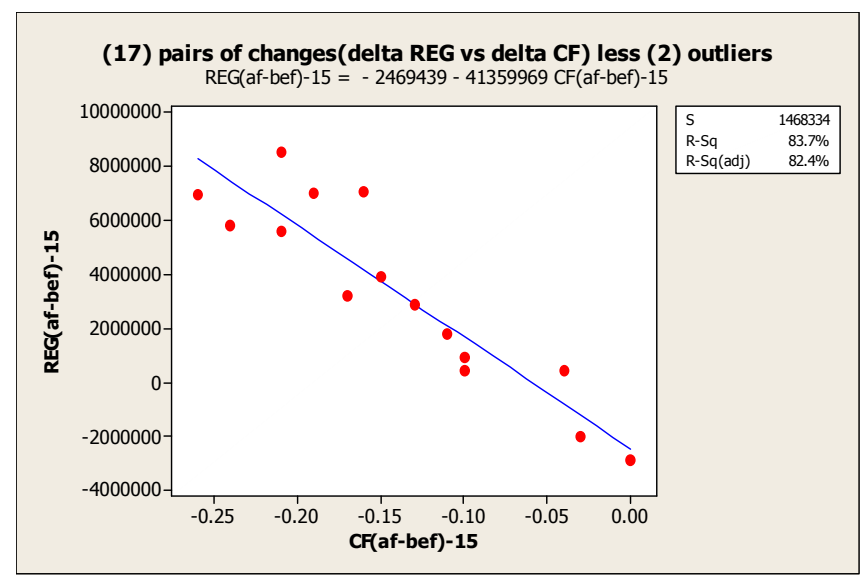

Fig.16: Correlation between REG and carotid flow pulse amplitude changes in PEEP group.

\section{SAP decrease}

Determining optimal perfusion pressure for patients with traumatic brain injury can be accomplished by monitoring the pressure reactivity index, or PRx, which requires an intracranial pressure monitor $[58,60,61]$. We hypothesized that pressure reactivity could be quantified using a REG index, or REGx. We measured the REGx and PRx as repetitive, low-frequency linear correlation between arterial blood pressure and intracranial pressure (PRx) or arterial blood pressure and REG pulse amplitude (REGx) in a piglet model of progressive hypotension. We compared the PRx and REGx against a gold standard determination of the lower limit of autoregulation using laser-Doppler measurements of cortical red cell flux. The PRx produced an accurate metric of vascular reactivity in this cohort, with area under the receiver-operator characteristic curves of 0.91 . REGx was moderately correlated to the PRx, (Spearman $r=$ $0.63, \mathrm{p}<0.0001)$. The area under the receiver-operator curve for the REGx was 0.86. Disagreement occurred at extremes of hypotension. For further details see [58].

\section{Liposome injection}

Methods: Pigs were anesthetized with $2 \%$ isoflurane. Twenty-four male Yorkshire pigs were used (weight 49.77 $\pm 28.25 \mathrm{~kg}$ ), and 19 types of liposomes were injected in 57 trials. A Doxil subgroup $(n=12)$ was also separately analyzed. REG was measured by two stainless steel electrodes $(5 \times 20 \mathrm{~mm})$ placed on the skull over the parietal and frontal bone of each pig using stainless steel screws. A Bovie gel conductor (Sybron, Rochester, NY) was layered between the bone and the electrode. The electrodes were placed apart from the sutura sagittalis symmetrically; the interelectrode distance was $12-35 \mathrm{~mm}$. The electrodes were covered with dental acrylic cement (Cranioplastic Powder, Plastics One, Roanoke, VA). An electrical impedance amplifier (Galileo) was used. Basic inter-electrode resistance was 3-5 ohms: this was the value read on a 10-turn potentiometer. This value involves both contact resistance and tissue resistance; it was not possible to measure them separately with this device.

Results: A transient but significant decrease of REG pulse amplitudes followed the injection of liposomes (78.43 $\%$ in the total sample, and $91.66 \%$ in the Doxil subgroup; P $=0.003, \mathrm{n}=12$ ), indicating the involvement of cerebrovascular reaction during liposome infusion. For details, see [54].

\section{Monkey: Calculation of lower limit of $C B F A R$}

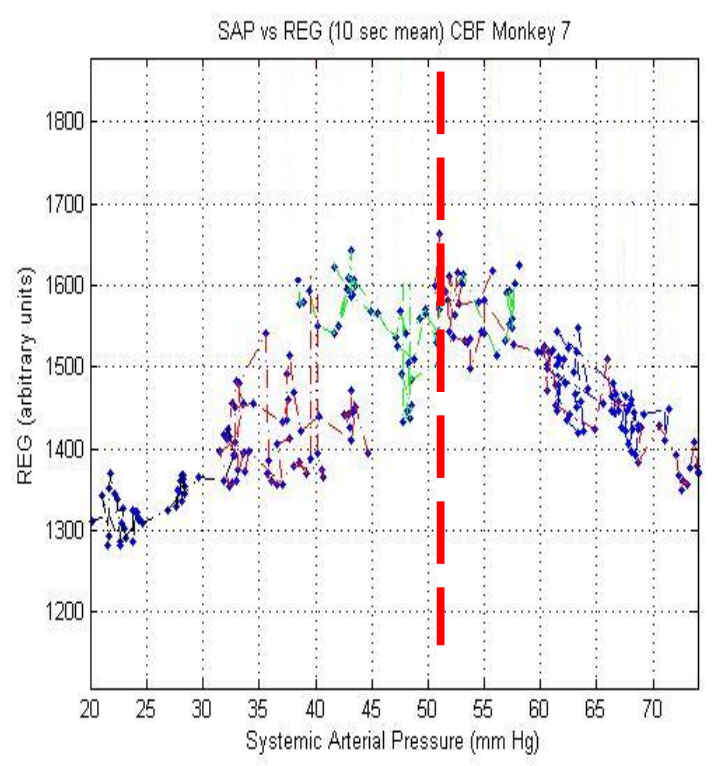

Fig.17: Relationship of REG to systemic arterial pressure during lethal hemorrhage. The shape of this relationship strongly suggests that the REG signal is reflecting the cerebral vasodilation that occurs over the range of SAP from 90 to $50 \mathrm{~mm} \mathrm{Hg}$. The negative Pearson coefficient indicates the presence of autoregulation in this range and a positive Pearson coefficient below $50 \mathrm{~mm}$ $\mathrm{Hg}$ indicates the absence of autoregulation.

Methods: Eight Rhesus Macaques were measured with 6.61 $\pm 1.26 \mathrm{~kg}$. Preparation and measurement was similar to pigs. The differences were that REG was recorded by surface electrodes, placed on the forehead (ECG electrodes: 
SF403, ConMed, Tyco Healthcare, Mansfield, MA). REG amplifier was Cerberus. The calculation of lower limit of CBF AR was performed during lethal hemorrhage. Pearson's correlation coefficient was calculated in Matlab (Natick, MA) for determination of lower limit of CBF AR [61-63].

Results: This study demonstrated that with surface electrodes REG can be used to detect lower limit of CBF AR.

\section{Human studies}

\section{$\mathrm{CO}_{2}$ inhalation}

$\mathrm{CO}_{2}$ inhalation caused increase in cerebral blood volume, measured by radioiodinated human serum albumin (RIHSA) and REG pulse amplitude [32].

\section{Evaluation of commercially available electrode materials}

Bioimpedance can be used for peripheral pulse detection as a non-invasive method for continuous vital sign monitoring. The objective of this study was to evaluate the commercially available electrode materials that might be useful as wearable electrodes for the measurement of bio-impedance pulse wave, to measure bioimpedance pulse variability, and test pulse detection (not only bioimpedance) sensitivity. Here we present only REG related results, for details see [42].

Methods: Electrode down-selection was performed based on in vitro and in vivo studies. A total of 13 conductive materials and 13 subjects were measured. Arm cuff inflation was used to measure pulse sensitivity. A PC and Cerberus were used for data collection.

General measurements were performed as follows: a 9electrode cap (5 scalp EEG + 4 REG electrodes, ElectroCap International, Inc. Eaton, $\mathrm{OH}$ ) was placed on the head of each subject in a sitting position and filled with electrolyte gel (Nicolet Biomedical, Madison, WI). Electrode locations within the cap were as follows: (1) EEG (T5-O1 and T6-O2) recorded in bipolar configuration. EEG ground was Fz; (2) REG (Fp1-F7 and Fp2-F8) in bipolar derivation. Localization is given according to the International 1020 system of EEG [64]. Subjects were asked to lie in a supine position. For each subject, the conductive fabric was placed around both wrists and ankles; inter-electrode distance was $5 \mathrm{~cm}$. The electrode cap and the peripheral electrodes were connected to Cerberus system. The Dinamap Pro1000 (GE Medical Systems, Milwaukee, WI) was used to obtain blood pressure and heart rate measurements prior to the testing of each conductive fabric; 10 blood pressure recordings were made. Blood pressure and its derivatives, ECG, EEG, and REG were also measured as a potential source of biological variability. Five 1-minute recordings were acquired. After the fifth recording, the conductive fabric was changed, and blood pressure measurements and recordings were repeated for each fabric.
Results - REG: For all healthy subjects, physiological cerebrovascular aging was expected to show an identical slope with age. The REG anacrotic time showed a nearly identical slope for both REG and age, fig. 18.

Table 3: Numeric characteristics of REG anacrotic time and age. REG samples were analyzed dividing into subgroups according to age: young (17-28) and old (42-55). * p-values of difference between young and old group.

\begin{tabular}{lcccc}
\hline & \multicolumn{2}{c}{ young } & \multicolumn{2}{c}{ old } \\
& Age & REG & Age & REG \\
& year & ms & year & ms \\
\hline Mean & 22,33 & 65,50 & 47,57 & 60,71 \\
SD & 4,37 & 8,34 & 4,58 & 5,65 \\
Count & 6 & 6 & 7 & 7 \\
p & & & $>0,0001^{*}$ & $0,0001^{*}$ \\
\hline
\end{tabular}

Conclusion: Reproducibility and sensitivity of the bioimpedance measurement, including REG, were comparable to the sensitivities of the pulse oximeter, laser Doppler, and Doppler ultrasound. There was no statistical difference between the bio-impedance measurement and the other techniques. Results demonstrated that bio-impedance offers potential for use as a multifunctional, continuous, noninvasive life sign monitor for both military and civilian purposes. For further details see [42].

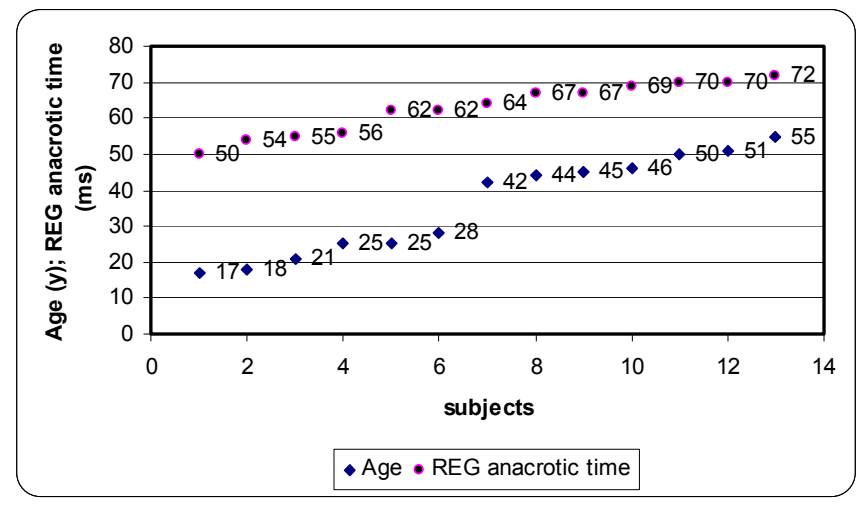

Fig.18: Sorted age and REG. Age and REG regression data (calculated as one group, $n=13$ ) are as follow: Age: $y=3.4505 x+$ 11.769, $\mathrm{R}^{2}=0.9509$, and REG: $1.7912 \mathrm{x}+50.385, \mathrm{R}^{2}=0.9527$ (both linear).

\section{Alcoholic patients}

Despite recent evidence of the beneficial effects of moderate alcohol consumption in arteriosclerosis prevention, the neurotoxic effects of alcohol abuse are well known. Our hypothesis was that uncontrolled alcohol consumption may cause cerebrovascular damage detectable by REG, measured by Cerberus system; detailed methods and results see [43].

Results: 1) The most important result of this study was that the longer REG anacrotic time was parallel to the higher quantity of daily alcohol consumption in the MAWI 
subgroup $(\mathrm{n}=12)$. BMI and MAWI dementia \% showed a statistically significant positive correlation $(r=0,599$; $\mathrm{p}=0,020$ ) in the same subgroup. The daily alcohol consumption correlated to 1) REG anacrotic time $\mathrm{r}=0,683 ; \mathrm{p}=$ 0,007; dementia \% vs. BMI: $r=0,599 ; \mathrm{p}=0,020$; Kerdo-2 index vs. risk factors: $r=0,610 ; p=0.018$; anxiety-2 vs. risk factors: $r=0,538 ; \mathrm{p}=0,036$.

2) In the same group, the five-item short form of an anxiety test (STAI, [66]) was administered twice during the same session. Between each test, brain pulse waves were recorded by REG. A REG peak time above 180 milliseconds was considered a cerebrovascular alteration (modified after Jenkner). Data were sorted into two groups: low anxiety $(\mathrm{N}=10)$ and high anxiety $(\mathrm{N}=10)$. Significant differences were found between cardiovascular risk factors $(\mathrm{p}<$ $0.001)$, REG peak time $(\mathrm{p}<0.043)$, and heart rate $(\mathrm{p}<$ 0.045). Six subjects showed cerebrovascular alteration in the high anxiety group, and two in the low anxiety group. For the two anxiety groups, there were no significant differences in body mass index, cardiovascular sympatheticparasympathetic balance, age and symptoms of transient ischemic attack. The correlation of REG and age was significantly different only for the alcoholic subgroup, detailed elsewhere [44]. These data support the hypothesis that a correlation exists between cerebrovascular disorder and anxiety in the studied population.

\section{A comparative population screening with Cerberus system}

The first results ( $\mathrm{n}=140$ subjects) gained with the breadboard version of Cerberus was presented at Kuopio ICEBI Conference [34]. The assumption of the present study, conducted by the National Stroke Program in Hungary from 1992 to 1994, was that individuals at high risk for cerebrovascular disease can be identified through mass screening (Csengersima'92 study). For the study, a computer-based screening device ("Cerberus") was developed and tested for use in the study [35-38].

The objectives of the study were as follows: (1) to collect and compare the prevalence of known CVD and stroke risk factors in a specific population in order to identify individuals at high risk for cardiovascular disease (CVD) generally and specifically for stroke; 2) to validate REG measurements obtained with an experimental screening device ("Cerberus"); 3) to compare the results of REG measurements with results obtained using Doppler ultrasound; (4) to compare the survey results obtained in this study with data collected from prior medical records of the same screened population.

Methods: A sample of 546 non-symptomatic (selfdescribed) volunteers ranging in age from 14 to 83 years participated in the study (a cross-sectional survey).

Medical records were available for 330 (211 female, 119 male) of the 546 non-symptomatic volunteers. Stroke risk factors for these subjects were estimated by comparing their records with the answers on their Cerberus questionnaires.

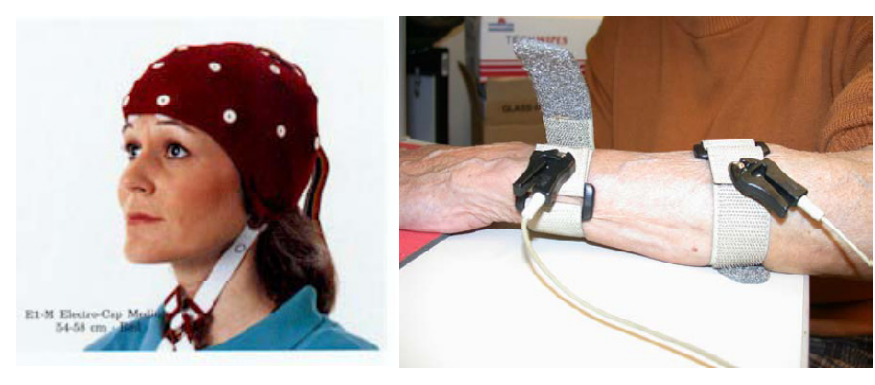

Fig.19: REG and EEG electrodes in electrode cap (left) and peripheral electrodes (right).

The sample was evaluated according to the full protocol, which included blood chemistry, ECG, Doppler control, and Cerberus testing. The analyzed REG sample involved 457 subjects, 309 female and 148 male. Psychological tests and comparative analysis were part of the full protocol; detailed elsewhere [39,40].

For 252 subjects, Doppler ultrasonography (B mode or duplex scan, Ultramark 4 and Apogee, ATL, USA) was used to measure carotid stenosis. Mean velocity for "out of normal range" (pathological blood flow) was considered as above $40 \mathrm{~cm} / \mathrm{sec}$. Additional details see [40].

\section{Cerberus Measurement}

The Cerberus system was described in detail elsewhere $[35,36]$. Briefly, it is a computer-based inquiry employing Magic(C) software and additional modules developed specifically for Cerberus applications. The examination requires about 20 minutes and can be administered by a technician. A professional trained in vascular neurology interprets the results, contained in a graphically illustrated summary. It is possible to give each subject a report at the conclusion of the examination, indicating (1) healthy, (2) cerebral blood flow disturbance, (3) peripheral blood flow disturbance, (4) neurological or internal medical disturbance, (5) other.

First, a questionnaire was administered, blood pressure was measured. The questionnaire addressed demographics, anxiety (STAI) [66], stroke risk factors, and neurological symptoms indicating possible past transient ischemic attack (TIA). Then, multichannel polygraphic recordings were made as follows: 1) ECG; 2) EEG from T5-O1, T6-O2 according to the 10/20 system of EEG with ECI System (Electro-Cap Int'l, Eaton, OH); 3) bio-impedance pulses of head (REG) derived from Fp1-F7 and Fp2-F8 (according to international EEG electrode localization) and of limbs (both sides) with circumferential electrodes (RHEOSCREENC, Germany). Following a one minute polygraphic recording, blood pressure was re-measured, and the STAI was repeated; analog - digital conversion was $275 \mathrm{~Hz}$.

Custom software was developed for Cerberus to perform the following signal processing procedures: display of analog physiological signals [65] calculation of fast Fourier transform (FFT) from EEG; averaging of pulse curves; determination of dominant frequency peak for EEG and of minimum/maximum values for REG and peripheral pulse waves. REG was considered arteriosclerotic if its anacrotic 
portion was above the $180 \mathrm{~ms}$ threshold, modified after Jenkner [13].

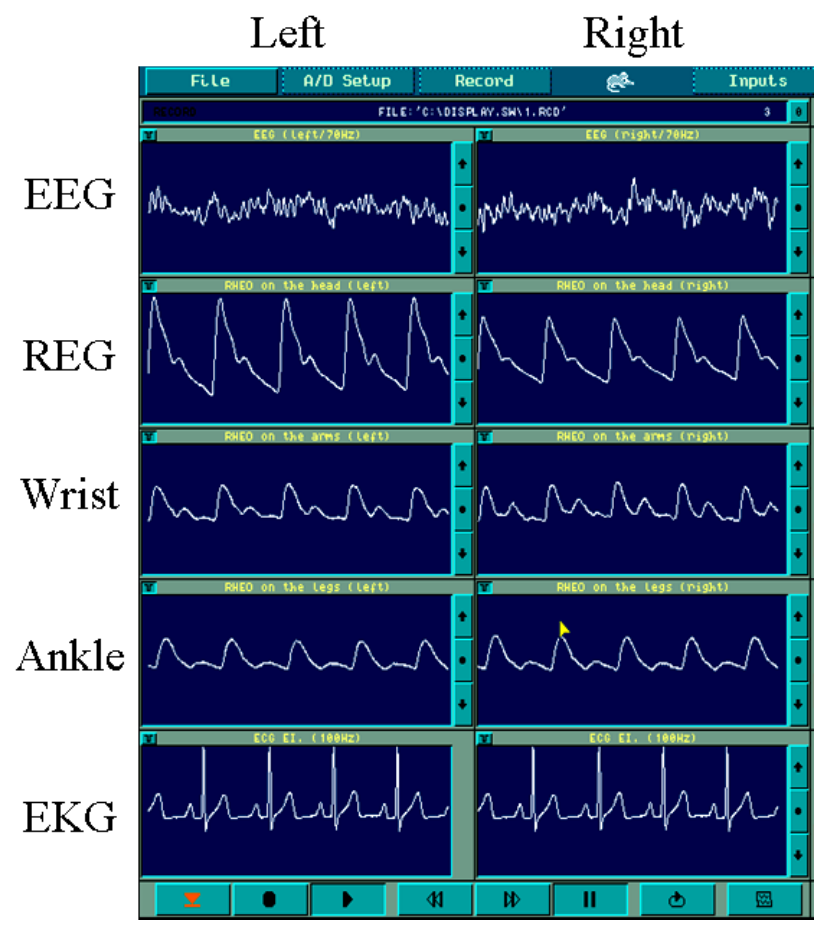

Fig.20: Cerberus traces on left and right side (ECG is the same on both side); Redirec screen [65].

From data collected by measuring blood pressure and heart rate using an automatic device, the Cerberus software calculated the ergotrop/trophotrop ratio (modified vegetative balance by Kerdo and Sipos: 1 - (diastolic blood pressure/HR) x 100 [36]. Body mass index (BMI) was calculated as weight $(\mathrm{kg}) /$ height $(\mathrm{m})^{2}$. Overweight was defined as $\mathrm{BMI}>25$ for male and $\mathrm{BMI}>23.8$ for female, respectively.

Data analysis: Artifact contaminated recordings were excluded from further processing (REG, ECG). For statistical treatment and analysis, Framework and Excel software were used. In most cases, results for male and female subjects were calculated separately (for REG data, where hemispherical differences were less than $5 \%$, female and male groups were analyzed together). After the automatic measurement of REG, a second REG calculation was made off-line to calculate the first derivative parameter $(n=390)$.

Results: REG anacrotic time was significantly correlated with age and vegetative balance; there were no gender differences. REG was significantly correlated to systemic arterial pressure in females. The most significant observation in regard to REG anacrotic time was related to age: both REG anacrotic time and the time interval between ECG R peak and peak of REG first derivative increased with age. Lateral differences in REG amplitude, REG anacrotic time and the derived flow index [12] were found more frequently in middle aged groups (age 40 to 60 ) than in younger or older groups.

For $52.78 \%$ (male) and $55.8 \%$ (female), a sclerotic REG curve was observed. The slope of regression function for REG vs. age was $3.195 \pm 0.45$ for females, $2.96 \pm 0.62$ for males. The age dependency of sclerotic brain arteries by REG was highly significant, above all other risk factors [38].

Significant correlations were observed between somatic and psychological variables, for details [39]. In all subjects who were found arteriosclerotic by REG measurement, the REG pulse wave was altered; however, for most of these patients, the EEG spectral parameters were in the normal range, and the Doppler control showed no pathological alteration. The regression line of the REG anacrotic time vs. age had a slope 10 times sharper than that of Doppler systolic velocity.

Additional data for correlation of CVD risk factors were detailed elsewhere [40].

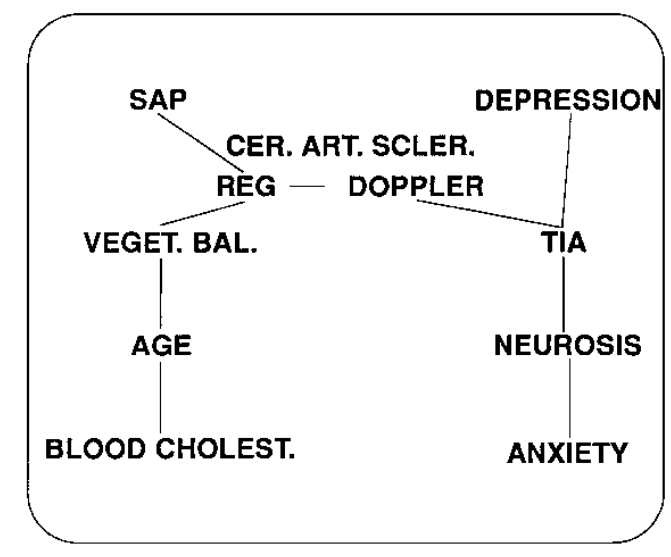

Fig.21: Significant correlations among measured variables. Cerebrovascular alteration (REG-Doppler-TIA) was in a bridge position between measured somatic (left) and psychological (right) variables $(n=546, p<0.05)$. Legend: SAP: systemic arterial pressure; cer. art. scler: cerebral arteriosclerosis; REG: rheoencephalogram; Doppler: carotid flow systolic velocity measured by Doppler ultrasound; veget. bal: vegetative balance by KerdoSipos; cholest: blood level of total cholesterol; TIA: symptoms of transient ischemic attack entered into Cerberus inquiry.

Conclusion: In this study REG measurements revealed symptoms of arteriosclerosis in $54.26 \%$ of our subjects; within the identical population, the Doppler ultrasound measurements showed $30.43 \%$ with arteriosclerosis. The difference of regression lines between REG anacrotic time and Doppler systolic velocity showed similar picture, which can be interpreted as increased sensitivity of REG.

As a summary of our results we can conclude, that the earliest manifestation of cerebral arteriosclerosis is the lost elasticity of cerebral arteries, which can be detected by REG. This information is even more practical and more important than the presence and prevalence of a single stroke risk factor.

The present study validated our initial hypothesis - that Cerberus (REG measurement) would predict the presence of cerebral arteriosclerosis in the susceptibility/presymptomatic "upstream phase" phase [51], earlier than Doppler ultrasound measurements. The explanation of this difference can be based upon the development of arteriosclerosis [67]. 


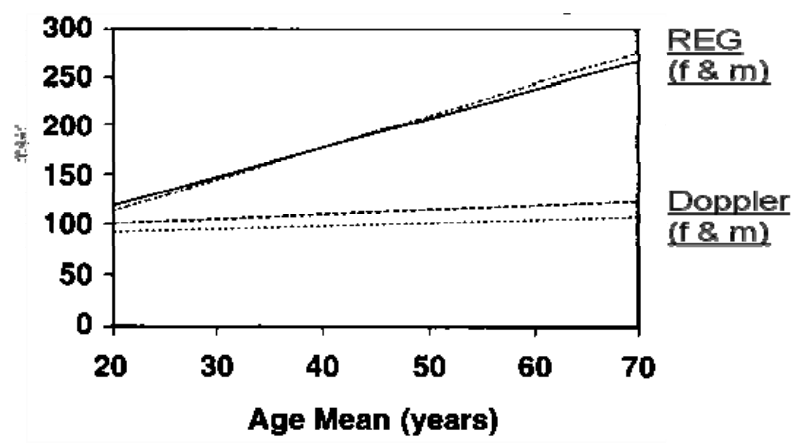

Fig.22: Comparison of slope of age regression lines (REG anacrotic time and Doppler systolic velocity). REG anacrotic time ( $\mathrm{Y}$ axis in ms: REG anacrotic rise time) and Doppler systolic flow velocity ( $\mathrm{Y}$ axis not shown) of internal carotid artery are plotted as a function of age (X axis). The regression lines of male and female groups are similar, but the slope of REG is about ten times steeper than that of the Doppler curve. f: female, m: male. Reprinted courtesy of Health Quest Publications Anti-Aging Medical Therapeutics, Vol. II. [38].

The present study validated our initial hypothesis - that Cerberus (REG measurement) would predict the presence of cerebral arteriosclerosis in the susceptibility/presymptomatic "upstream phase" phase [51], earlier than Doppler ultrasound measurements. The explanation of this difference can be based upon the development of arteriosclerosis [67].

\section{Expert system}

The statistical performance rate of the test run is as follows. We expect in $47 \%$ of the cases a correct class prediction, in $24 \%$ an inconclusive result, in $7 \%$ of the classes the result that "no rule applies" and in $22 \%$ of the cases an incorrect conclusion. In other words if the expert reaches a conclusion, we know that it is a correct conclusion in $68 \%$ of the cases and an incorrect one in $32 \%$ of the cases [41].

\section{Clinical background for REG}

\section{Cerebral Blood Flow}

The brain has ongoing, substantial energy requirements but minimal stores of energy-generating substrates. As a result, it is completely dependent on a continuous, uninterrupted supply of substrate (oxygen, glucose). Although the demand by the brain for energy-generating substrates is substantial (the central nervous system consumes $20 \%$ of the oxygen (that is, $170 \mathrm{mmol} / 100 \mathrm{~g}$ per min or $3-5 \mathrm{ml}$ $\mathrm{O}_{2} / 100 \mathrm{~g}$ brain tissue per $\mathrm{mm}$ or, approximately, $40-70 \mathrm{ml}$ $\mathrm{O}_{2} / \mathrm{min}$ ) and $25 \%$ of the glucose $(31 \mathrm{mmol} / 100 \mathrm{~g}$ per $\mathrm{mm}$ ) utilized by the resting individual under physiological conditions, this is met more than adequately by the $15 \%$ of the resting cardiac output $(750 \mathrm{ml} / \mathrm{mm})$ which perfuses the brain $($ mean global CBF $)=50 \mathrm{ml} / 100 \mathrm{~g}$ brain tissue per $\mathrm{mm}$ (range $45-55 \mathrm{ml} / 100 \mathrm{~g}$ per $\mathrm{mm}$ ) approximately $80 \%$ to grey matter and $20 \%$ to white matter). Indeed, normally, the supply of oxygen (approximately $150 \mathrm{ml} \mathrm{O} 2 / \mathrm{min}$ ) is consi- derably in excess of requirements (around 40-70 ml $\mathrm{O}_{2} / \mathrm{min}$ ) such that the brain extracts only $25-30 \%$ of that supplied. In addition, the brain can conserve energy and, hence, decrease demand by switching off many of its metabolic processes before its reserves have been compromised when the delivery of substrate reaches 'critical' values.

However, the flip side of this argument is that, paradoxically, the brain cannot tolerate significant increases in the volume of the contents of the rigid container in which it is enclosed. Moreover, because the brain's own store of energy-generating substances (glycogen/glucose, oxygen) is small (so small that, at normal rates of adenosine phosphate production, the stores of glycogen in the brain would be exhausted in less than $3 \mathrm{~min}$ ) it is uniquely dependent on a continuing, and adequate supply of substrate [68]. The automatic servo mechanism, which is the first line of defense of the brain, called CBF AR.

\section{Clinical background: CBF Autoregulation}

CBF AR in the cerebral circulation may be defined more pragmatically as the mechanism that protects the brain against the dangers of hypoxia at low perfusion pressures and against the risks of brain edema at high arterial pressures. Based on this definition, cerebral autoregulation may be thought of as a homeostatic mechanism that is superimposed over and above the baroreceptor reflexes. The baroreceptors, strategically located at the most proximal locations in the cerebral circulation, provide the first line of defense against acute ranges in arterial pressure. Autoregulation then serves as the next line of defense by helping to maintain constant cerebral capillary pressure, thus assuring a steady supply of essential metabolites and simultaneously protecting the blood-brain barrier. Several hypotheses (myogenic, neurogenic, and metabolic) have been proposed to account for the mechanisms that underlie autoregulation, detailed elsewhere [69]. The anatomical background of $\mathrm{CBF}$ autoregulation is the arteriole. The arteriola in the brain constrict or dilate in response to changes in blood pressure between about 50 to $150 \mathrm{mmHg}$ SAP. These limits are not entirely fixed but can be modulated by sympathetic nervous activity, the vascular renin-angiotensin system, and any factor (notably changes in arterial carbon dioxide tension) that decreases or increases CBF. Disease states of the brain may impair or abolish CBF autoregulation. Thus, autoregulation is lost in severe head injury or acute ischemic stroke, leaving surviving brain tissue unprotected against the potentially harmful effect of blood pressure changes. Likewise, autoregulation may be lost in the surroundings of a space-occupying brain lesion, be it a tumor or a hematoma [70]. Below and above this limit or in pathological cases, CBF passively follows systemic arterial pressure. Beyond the lower limit of autoregulation, vessels passively collapse, and ischemia results. Beyond the upper limit of autoregulation or the "breakthrough zone", increased intravascular volume and pressure results in vasogenic edema 
[71]. Overview of brain injury, brain monitoring were detailed elsewhere $[4,72,73]$.

\section{Lower limit of CBF autoregulation}

Monitoring the lower limit of CBF autoregulation has been introduced into clinical practice with invasive modalities such as ICP and SAP [62]. The slow oscillations of SAP are the input information in transfer analysis of ICP to be used to determine the lower limit of CBF AR [63].Using REG and non-invasive arterial pressure measurement the same information can be obtained - non-invasively. Noninvasive blood pressure monitors are used in humans to obtain arterial waveform and perform cited monitoring. This monkey study demonstrates that with surface electrodes (non invasive), the slow wave oscillations of the REG signal are present (not filtered out by the skull) and with specialized algorithms, REG can be used to detect lower limit of CBF AR. This result worth to compare with those of others discribing the influence of scalp influence on REG [74-77].

\section{Clinical background: Neuro-Monitoring}

The goal of neuro-monitoring is to prevent secondary brain damage. In the presence of a severe head injury, hypotension may result in a secondary brain injury and a worse outcome due to insufficient brain blood flow; when combined with severe head injury, hypotensive resuscitation may increase mortality by a factor of four [78]. For example, Current Combat Casualty Care guidelines recommend hypotensive resuscitation for treatment of injured soldiers $(70 \mathrm{mmHg})$; but in case of TBI the requested target arterial pressure of resuscitation should be $90 \mathrm{mmHg}[79,80]$. Monitoring of CBF AR is used in clinical practice, however, the most frequently used method, Doppler ultrasound, is far from optimal for this purpose since Doppler ultrasound typically does not offer continuous monitoring.

In the brain the function, metabolism - flow has a close coupling until ischemia disconnect this relationship. The ideal, non-existing, brain monitor would monitor all of these modalities. Also, the ideal brain monitor would indicate the point at which the first occurrence of irreversible brain damage occurs [81]. The goal of neuro-monitoring is to prevent secondary brain damage by maintaining CBF; neurophysiological monitoring during surgery has two main objectives: first, to warn of imminent damage to the nervous system, and second, to guide optimal management of anesthesia [82].

One of the basic challenges in neurocritical care is monitoring brain-related vital signs: ideal monitors should be noninvasive and continuous. However, invasive and often non-continuous techniques are typically in use. Moreover, most ICU noninvasive circulation monitors do not supply satisfactory information about the brain. For example, in the case of increasing ICP in a hypotensive patient, the Cushing reflex [83] involves elevation of SAP; therefore,
SAP monitoring alone does not supply sufficient information to allow for a differential diagnosis and adequate therapy. Quantitative brain imaging methods typically in use today were not designed for continuous monitoring. Even though brain perfusion, ICP and tissue oxygen level monitors generate continuous signals, they are invasive techniques. Similarly, although Doppler ultrasound is noninvasive and provides quantitative $\mathrm{CBF}$ monitoring, it has practical disadvantages in that the probe-holding frame is inconvenient to use; consequently recording typically takes place only one or at most a few times per day and is not continuous.

The limitations of most existing monitors used to measure $\mathrm{CBF}$ are that they measure only a small volume of brain tissue and are therefore not indicative of total CBF (e.g. LDF) or they measure an area (e.g. carotid artery) that does not accurately reflect $\mathrm{CBF}$ in the brain tissue itself. Since $\mathrm{CBF}$ is heterogenous both at rest and during hemorrhage $[84,85]$, most monitors reflect regional flow for only a small volume of brain tissue. Therefore, values for regional flow may not reflect global CBF. Existing brain mapping techniques that offer quantitative CBF have good space resolution but bad time resolution. Such techniques were not designed for continuous $\mathrm{CBF}$ monitoring. The ideal CBF monitor would measure global CBF with excellent time resolution.

Another CBF monitoring problem is the anatomical differences among arteries involved in $\mathrm{CBF}$ autoregulation, which are size dependent. The effector organ of CBF autoregulation is the arteriola [86]. This fact partly explains the different findings using different CBF measurement techniques. Consequently, the arteriolar change observed in brain by REG reflects arteriolar function more than it reflects functions in larger arteries (e.g. carotid). Indirect CBF measurements such as EEG are unable to detect minimal ischemia until it causes failure in synaptic transmission [69].

CBF reactivity monitoring is an appropriate primary parameter to evaluate cerebral resuscitation due to a systemic or regional cerebral injury leading to possible irreversible brain injury. Unlike CBF monitoring this technique of CBF reactivity is being proposed as a non-invasive, mobile, and non-operator dependant means of evaluating an unconscious patient.

Technical aspects of CBF monitoring by REG and comparison to the Doppler ultrasound were detailed earlier. Use of REG for continuous noninvasive monitoring has potential advantages to Doppler, particularly in non-hospital settings, such as military and emergency medicine, where technical challenges of $\mathrm{CBF}$ monitoring are much greater than in the normal civilian hospital milieu $[87,88]$.

Brain injured patients are known to have compromised autoregulation, but currently there is no non-invasive way to assess the risk of implementing a hypotensive resuscitation strategy in the brain- injured patient. REG can identify the autoregulatory breakpoint for individual patients to determine their limit for permissive hypotension or start 
infusion to increase cerebral perfusion pressure. Introduced findings support the application of REG as a neuromonitoring modality; additional REG correlative studies are in progress.

\section{Clinical background: $C B F$ reactivity}

In clinical practice reactive brain vessels offer a positive prognosis; non-reactive vessels are a bad prognosis and call for medical intervention. CBF autoregulation is measured as a routine test using Doppler ultrasound [89,90]. Our previous findings $[47,48,53]$ and the REG literature $[13,14]$ indicate that REG reflects the functioning of arterioles and may offer better CBF monitoring than the Doppler technique since Doppler measures $\mathrm{CBF}$ autoregulation in larger arteries. Various $\mathrm{CO}_{2}$ reactivity tests are used to challenge $\mathrm{CBF} \mathrm{AR}$, such as breath holding, hyperventilation, $\mathrm{CO}_{2}$ inhalation. The constancy of $\mathrm{CBF}$ and volume relies heavily upon the cerebral arteries' intrinsic ability to respond to changes in the partial pressure of arterial $\mathrm{CO}_{2}$. The physiologic mechanisms underlying these responses have not been determined, although changes in extracellular and intracellular $\mathrm{pH}$, mediation by prostanoids and neural activity have been suggested. $\mathrm{CO}_{2}$ reactivity can be influenced by oxygen status and blood pressure and can vary according to age and brain region. In certain pathological conditions or diseases, it can be severely altered. Modern techniques, which measure CBF in cases of cerebral hemodynamic insufficiency, head injury or tumor, rely on the inherent ability of the cerebral circulation to respond to changing levels of $\mathrm{CO}_{2}$ [91]. Additional CBR AR tests are rapid deflation of thigh cuff, Trendelenburg and inverted Trendelenburg position and Valsalva maneuver.

As a comparison, the difference between reaction time of various arterial pressure control mechanisms (maximum feedback gain at optimal pressure) are in seconds range are baroreceptors, chemoreceptors and central nervous system ischemic response [92]. REG represents the latest.

\section{Clinical background: Positive end-expiratory pressure (PEEP) and brain protection}

PEEP has desirable effects on blood oxygenation in the diseased lung. However, PEEP ventilation has an adverse cardiovascular response, which limits its utilization. Elevated intrathoracic pressure due to PEEP has the potential for increasing ICP and reducing SAP. Such changes could critically reduce cerebral perfusion pressure: $\mathrm{CPP}=\mathrm{SAP}$ ICP [93-97]. Decreased CBF, if great enough, can cause both brain ischemia and secondary brain damage. Monitoring CBF during PEEP would give physicians feedback, allowing them to treat patients safely when protecting the brain $[98,99]$, such monitoring is not part of typical clinical practice. To be successful, such brain monitoring must be continuous, non-invasive and simple to administer. REG potentially offers such a method: when CBF AR was ab- sent, REG and CF identically detected the absence of $\mathrm{CBF}$ AR. PEEP can be used to test CBF AR.

\section{Clinical background: Arteriosclerosis and REG}

Earlier studies have shown that atherosclerosis often begins with an increased intima thickness in the carotid bifurcation area. Such studies have suggested that disease development be followed over time by repeated imaging of the arterial wall, utilizing the Doppler ultrasound technique to measure the intima-media thickness (NASCET, ACAS, ARIC, PORT); recent clinical practice is based upon such information.

Arteriosclerosis has been described as a progression that occurs in two phases. The first phase occurs at a "slow rate" (related to accumulation of foam cells, creation of fatty streak, transformation of lipoid accumulation to crystalline cholesterol and accumulation of cellular components such as smooth muscle cells and fibroblasts. During this phase, changes occur in the elasticity of the artery wall but not in the lumen, and there is generally a form of compensatory remodeling of the external elastic lumina and muscular wall that allows preservation of the luminal to conduct blood flow. The second phase of arteriosclerosis occurs at "a rapid rate" (related to plaque fissuring and/or hemorrhaging leading to platelet rich thrombus accumulation [67]. During this phase, there are changes in the lumen as well as the artery wall. These two phases may correspond to the known stages of prevention levels of chronic disease, called "upstream" (prevention level 1-2) and "downstream" (prevention level 3-4) [100].

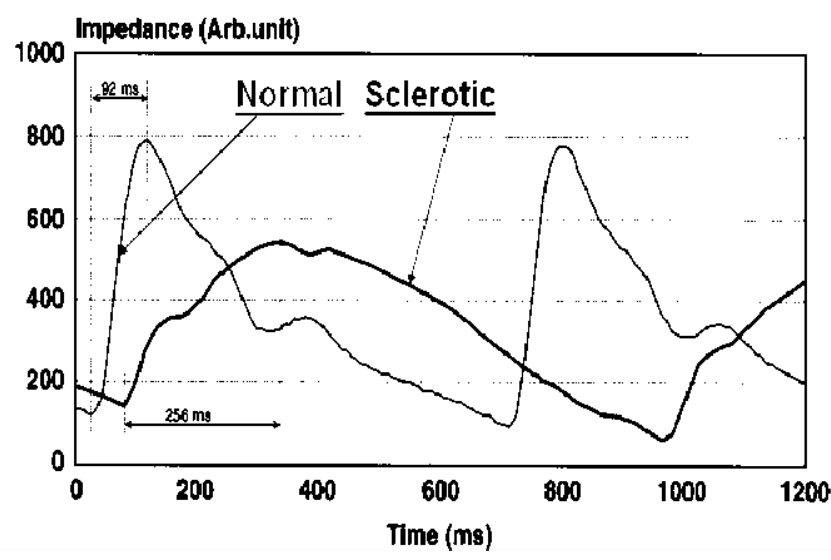

Fig.23: Typical REG curve of a healthy (normal) and a sclerotic person. Note the difference in peak time of REG curves for normal patients (92 milliseconds) and sclerotic patients (256 milliseconds). This difference has pathological meaning, independent of heart rate. Reprinted courtesy of Health Quest Publications AntiAging Medical Therapeutics, Vol. II [38].

Arteriosclerotic REG normative was offered by Jenkner, who averaged REG pulses from 100 phases of each patient of 178 normal subjects and 246 patients with proven cerebral arteriosclerosis [13]. Using these data REG anacrotic time above $180 \mathrm{~ms}$ was considered pathological in Cerberus system. Although have been developed computation of the REG signal, these software were not specifically designed for use in the diagnosis of brain arteriosclerosis [101-104]. 
A typical REG change (fig. 23) is known to occur as a consequence of arteriosclerosis, expressed as elongation of REG pulse amplitude peak time or decreased slope of anacrotic part [13]. The possible cause of this alteration is the decreased elasticity of arteriolar wall, which is the most sensitive indicator of disease progression or decreased "windkassel" (compression chamber) function. In a population survey of arteriosclerosis comparing REG and Doppler ultrasound systolic velocity, REG was a more sensitive indicator than Doppler. This information will be discussed in more detail later in this chapter.

The present human study identified subjects with decreased brain arteriolar elasticity using REG, which detected CVD/stroke risk at the susceptibility or presymptomatic phase. In general: subjects who showed no cerebrovascular alternations when measured by EEG revealed such cerebrovascular alterations when measured by REG. The explanation is that in the early stages of atherosclerosis, blood supply to the brain is sufficient, and subjects therefore have no detectable symptoms or EEG alteration. In other words: Doppler can detect the manifested artery alteration, and REG can detect the lost elasticity of artery wall before remodeling.

Animal studies confirmed that REG is more sensitive than Doppler ultrasound in reflecting CBF autoregulation $[47,48,53]$. The background of this sensitivity difference is that brain vessel responses (CBF autoregulation) have been found to be size dependent: small arterioles (less than 100 $\mu \mathrm{m}$ in diameter) dilated only at a pressure equal to or less than $90 \mathrm{mmHg}$; below $70 \mathrm{mmHg}$, their dilatation exceeded that of larger vessels [105]. A correlative sensitivity difference was found when REG detected cerebral arteriosclerosis at an earlier stage and in a greater percentage of subjects than did Doppler. REG is therefore more effective as a means of primary stroke prevention [106]. It is estimated that Cerberus system can detect cerebral arteriosclerosis from 5-15 years earlier than the Doppler technique. Earlier detection of the stroke prone population allows more time for precise etiological diagnosis and facilitates earlier intervention and therapy.

The study demonstrates a possible model for primary CVD/stroke prevention. The simple, noninvasive Cerberus test, which uses REG, offers a standardized method for mass screenings by identifying the population at high risk for CVD disturbances, especially cerebrovascular disease. The method also provides a model for storing analog physiological signals in a computer-based medical record. The screenings described here offer a cost-effective, practical way to allow individual physicians to identify patients in their care who are at high risk for CVD/stroke. In this model, REG can detect cerebrovascular disease in the susceptibility/ presymptomatic phase, earlier than the Doppler ultrasound technique. Consequently, the prevalence of the intracranial atherosclerosis can be higher measured by REG than Doppler ultrasound [107].

Arterial stiffening has been identified as a biomarker of stroke risk and indicator of large artery damage can be measured by pulse wave velocity [108]. It was known since the windkessel model described it [109]. Cerberus system measures it, but it was out of scope of recent overview.

\section{Clinical background: Spreading depression}

Spreading depression is an early warning sign of disturbed brain metabolism; it would be ideal for neuro-monitoring if it would be non-invasive. In humans, EEG measurements showing SD cannot be accomplished by placing electrodes on the scalp; such measurements require intra - or epicortical electrodes. REG measurement can be recorded with scalp electrodes - preventing any hazard of infection. The background mechanism of this phenomenon was described by Olsson et al [110].

\section{Clinical background: Liposome injection}

Intravenous administration of liposomes, including Doxil, a routinely used anticancer drug, can cause severe life threatening hemodynamic changes in pigs. The reaction is due to complement activation, and it is characterized by massive pulmonary hypertension, systemic hypotension and severe cardiac abnormalities including falling cardiac output, tachy- or bradycardia with arrhythmia. There were no data suggesting the involvement of cerebrovascular changes in this reaction, however clinical observations (nausea, vomiting, dizziness, headache) allowed this hypothesis. In this pig study a transient vasospasm was detected by REG following Doxil infusion. Liposomal formulations of drugs, among them doxorubicin (Doxil), have been developed and increasingly used in the treatment of cancer. Following liposome infusion in humans, frequently reported neurological symptoms include tremor, nausea, dizziness, fainting, panic attacks, and imminent fear of death. The unleashing of a wave of secondary vasoactive mediators may involve cerebrovascular reaction, formation of thromboxanes, leukotrienes, platelet activating factor and histamine. Based upon the above-mentioned facts, we hypothesized the involvement of cerebrovascular change during liposome infusion. Further details see [54,111]. This study can be an animal model of human vasospam. Vasospasm causes brain ischemia/hypoxia and secondary injury. It can develop after traumatic brain injury with delay even without physical impact, such as in case of blast injury [112].

\section{Clinical background: Metal fragments}

A major diagnostic limitation for the blast induced head injured patient is the inability to image the cranium due to the significant number of embedded metal fragments from improvised explosive devices, making MRI prohibitive. Additionally CT angiography sometimes fails to detect vasospasm due to the associated metal artifact $[112,113]$.

On the basis of preliminary results, REG seems to be a practical, noninvasive and continuous monitoring modality of traumatic brain and blast injuries. However, it is not 
known whether or not the presence of metal fragments affects the REG signal. This is why the impact of metal fragments on REG signal was tested. The present results of in vitro and in vivo studies confirmed the transient effect of metal fragment on REG. Additional studies needed to clarify the effect of metal size dependency and thermal impact.

\section{Clinical background: Vinpocetine injection}

Vinpocetine (Cavinton, Richter Ltd, Hungary) is a drug long time used in clinical practice and as a reference drug in pharmaceutical research. Some reports indicating its transient hypotensive effect [114-116]. In this study we used this transient hypotensive effect as a standard input to trigger CBF AR and compared REG changes to ICP. Both Cerberus and Galileo REG devices detected transitory REG pulse amplitude increase which correlated with ICP change. In clinical practice vinpocetine is infused intravenously: 20 $\mathrm{mg}$ vinpocetine in $500 \mathrm{ml}$ saline; this way the SAP decrease can be avoided [117].

\section{Impedance baseline level}

A measurement with MIC showed the opposite conductivity change in brain reflecting the conductive material presence $(0.9 \% \mathrm{NaCl}$ intracranial infusion) or absence (intracranial balloon inflation). The AC component and its first derivative however similarly increased in both cases.

\section{Data processing}

The best illustration of how REG development is a multidisciplinary subject can be followed by the used data processing. In 1970-es the REG filtering was realized by using analogue filter. Additional data processing modules were also built based on analogue circuitry [33]. From the 1980es a software development was used to support REG data processing; by this line 3 data acquisition system was created and used to collect, display and process REG and other signals (Gral, Redirec and DataLyser) [35,36,65,118]. In the mid-nineties an expert system approach was applied [41].

The REG signal is generated by bioimpedance amplifier using a Wheatstone bridge [119] and a joined differential amplifier. The tetrapolar system contains both AC and DC components; however, a bipolar system can produce only the AC component, and its output involves both positive and negative phases, similarly to the signal generated by differential amplifiers, such as EEG and EKG amplifiers. Its amplitude change as relevant biological information cannot be processed with a simple average reading and summarizing of the minimum - maximum distance of a pulse curve. The same problem occurs during calculation of the REG pulse integral; in both cases, negative numbers will be subtracted.
The main problem of REG data processing is the need to clean the REG signal from various artifacts and to identify the pathophysiologic background of alterations in the REG pulse wave. Biological artifacts include the following: 1) respiration (a subharmonic with the alternating frequency of respiration); 2) M-wave (a subharmonic of 3-9 oscillations per minute), which is the result of a sympathetic influence on SAP; and 3) a reflection of changes in ICP. Artifacts 1 and 2 were successfully decreased by used a filtering method and first derivative of REG pulse wave.

The usual method used to quantify a REG signal is similar to that of other pulse wave measurements-- amplitude (minimum maximum distance), its first derivative $(\mathrm{dZ} / \mathrm{dt})$, and integral measurement [6,102-104]. Both variables detected the applied CBF manipulations. The application of the REG derivative and integral has an advantage using computer data processing $[36,48]$.

Additional REG data processing problem is that REG is a biphasic signal, involving positive and negative values. Measuring such data was not a real problem on chart recorded trace: to measure the distance between minimum maximum of a REG pulse wave with a caliper automatically neglected this problem. It comes to be problem with digital signal processing: any calculation using negative of positive numbers (integral = area under curve, and mean) averages negative and positive numbers. In this case the biological information (REG amplitude increase or decrease) will be lost. The information is in the change of minimum - maximum distance of REG pulse wave, referring to vasoconstriction and vasodilatation.

Basic REG pulse wave variables were introduced previously. The most comprehensive theoretical approach for REG pulse wave analysis was overviewed by Sokolova $[102,103]$. The most comprehensive application in digital environment was realized by Montgomery called Rheosys [101]. Signal averaging [120] and minimal and maximum value calculation was used in Cerberus. Here was presented that the standard deviation values of REG pulse amplitude can be used for computed estimation of minimal-maximal distance values.

\section{Expert system}

Early screening helps to prevent the onset of diseases and reduces the health costs in general. Full automation of screening with low cost equipment can make large scale screening possible. The problem we are investigating is stroke, which is unique among neurological diseases since it has a high incidence rate, severe burden of illness, high economic cost, and it may be preventable [121]. The automation is achieved by the use of an expert system together with monitoring tools for screening the cerebral and vascular status of individuals to detect the initial stages of vascular disorders. This is a low cost system that runs on a PC platform (Cerberus) with some hardware for measurements.

Machine learning is the method used to discover hidden relationships in available data, so that this knowledge can 
be used to make predictions and decisions. This methodology is very useful for the applications to medical data which typically includes observations represented as attribute-value pairs and each observation is labelled with a class information such as diagnosis or treatment. The learning process involves classification and generalization. One of the advantages of machine learning methods in comparison to statistical approach is that machine learning can handle both qualitative information and quantitative information and is nonparametric, i.e., does not require a priori distributions. The information acquired by training on sample data is represented in some form which then can be used to predict the class membership of new observations.

In this work we use a machine learning method named CAN developed by one of the authors, that induces rules from data [41]. Rules are an attractive representation since they can be analyzed and understood well by experts and form a basis for an expert system. The available medical data set contained about 540 observations (data instances, Csengersima' 92 data base). Each data instance contained information about a patient in terms of several attributes such as sex, age, response to the questionnaire and measurements. The combined use of stroke risk factors, neurological symptoms and the measurements that include blood pressure, stress state and several polygraphic modalities (EEG, REG, EKG) are used by the experts to determine cerebral circulatory disturbances (and as a result the cases with a high risk of stroke), and to suggest further tests (see 5 evaluation possibilities in Cerberus questionnaire). The expert recommendations represent the class label for the observed patient data in attribute-value pairs.

The system is developed according the following steps. First, CAN induced rules through using the available medical data for training. Next, these rules are integrated into an expert system. Once the system has the data of a new patient available, the expert system made predictions about cerebral circulatory disturbances and identified patients with high risk of a stroke. The expert system goes through the typical match-execute cycle to make the predictions. An attractive feature of the methodology is that the rules the expert system used can be modified and improved incrementally by the learning system with the increase in the size of the patient data with class labels.

The statistical performance rate of the test run is as follows. We expect in $47 \%$ of the cases a correct class prediction, in $24 \%$ an inconclusive result, in $7 \%$ of the classes the result that "no rule applies" and in $22 \%$ of the cases an incorrect conclusion. In other words if the expert reaches a conclusion, we know that it is a correct conclusion in $68 \%$ of the cases and an incorrect one in $32 \%$ of the cases.

The result was quite good considering that we didn't use any polygraphic data. We would assume that attributes of REG will improve this drastically. Note: This decision is made by a machine. The doctor should confirm, reject or comment this decision.

\section{Conclusion}

The results presented here indicate that REG accurately reflects cerebrovascular responsiveness. REG pulse amplitude change reflects arteriolar, capillary and venular volume changes together rather than absolute brain blood flow.

The clinical importance of these findings is that REG can be measured noninvasively, continuously and more conveniently in humans than Doppler ultrasound. Therefore, measurement of CBF AR by REG has potential for use as a life sign monitoring modality; to realize it there is a supportive step on the way: United States Department of Defense made a solicitation to build a brain monitor involving REG [2].

REG is potential method for cerebrovascular diagnostics as well. In order to reach the potential of widespread application of REG, there is a need for further research to clarify additional (patho)-physiological correlations [122], adequate data processing and as Jenkner proposed in 1983, there is a need to create REG standards.

\section{Acknowledgements}

The authors thank people listed in cited publications for their help and technical assistance; Lajos Baranyi for use of DataLyser software, Milomir Simovic for Cavinton measurements, Janice Meer and Diana Temple for assistance with the manuscript. Two milestone contributors of this overview have to mention by names: Emil Pasztor, who initiated REG use for neuro-monitoring, and Frederick Pearce, who made it possible.

\section{Disclaimer}

The views expressed in this article are those of the author and do not necessarily reflect the official policy or position of the Department of the Navy, Department of Defense, nor the U.S. Government. The experiments reported herein were conducted in compliance with the Animal Welfare Act and in accordance with the principles set forth in the "Guide for the Care and Use of Laboratory Animals," Institute of Laboratory Animals Resources, National Research Council, National Academy Press, 1996.

\section{References}

1. Benabid AL, Balme L, Persat JC et al. Electrical impedance brain scanner: principles and preliminary results of simulation. TIT J Life Sci. 1978;8:59-68.

2. Anonymus. Solicitation: OSD09-H06 Neuromonitoring of traumatic brain/blast injury. Office of the Secretary Of Defense Small Business Innovation Research (SBIR) FY2009.3 http://www.acq.osd.mil/osbp/sbir/solicitations/ sbir093/osd093.htm. 
3. Anonymous. Rheoencephalography. In: Grimnes S, Martinsen OG, editors. Bioimpedance and bioelectricity basics, 2nd ed. Elsevier, Amsterdam, pp 351-353. 2008.

4. Rubin M, Yo M, Agostini M A, Madden J, Diaz-Arrastia RR. Noninvasive Monitoring. In: Jallo J, Loftus CM editors. Neurotrauma and critical care of the brain, Thieme, New York, 2009.

5. Patterson R. Bioelectric impedance measurement. In: Bronzino JD, editor. The biomedical engineering handbook. Boca Raton: CRC Press; 1995. pp 1223-1230.

6. Geddes LA, Baker LE. Principles of applied biomedical instrumentation. New York: Wiley; 1989.

7. Ringelstein EB, Van Eyck S, Mertens I. Evaluation of cerebral vasomotor reactivity by various vasodilating stimuli: comparison of $\mathrm{CO} 2$ to acetazolamide. J Cereb Blood Flow Metab. 1992;12:162-8.

8. Vastagh I, Pozsár M, Folyovich A, Debreczeni R, Pálvölgyi L, Bereczki D, Szirmai I. Intracerebral steal after acetazolamide administration. Ideggyogy Sz. 2008;61:168-73.

9. Anonymous. 21CFR882.1825. Rheoencephalograph. (a) Identification. Code of Federal Regulations. Sec. 882.1825. Washington, D.C. U.S. Government Printing Office, Vol. 8. Title 21, Parts 800 to 1299; revised April 1, 1997.

10. Waltz AG, Ray CD. Impedance cephalography ("rheoencephalography"). Trans Am Neurol Assoc. 1965;90:305-7.

11. Waltz AG, Ray CD. Inadequacy of "rheoencephalography". A clinical study of impedance cephalography for evaluation of cerebrovascular disorders. Arch. Neurol. 1967;16:94-102.

12. Nyboer J. Regional pulse volume and perfusion flow measurement. AMA Arch Internat Med 1960;105: 264-76.

13. Jenkner FL. Clinical Rheonecephalography. Vienna, Austria: Ertldruck; 1986

14. Moskalenko YE. Editor. Biophysical aspects of cerebral circulation. Oxford: Pergamon; 1980.

15. McHenry LC. Rheoencephalography: a clinical appraisal. Neurology. 1965;15:507-17.

16. Hadjiev D. A new method for quantitative evaluation of cerebral blood flow by rheoencephalography. Brain Res. 1968;8:213-5.

17. Jacquy $\mathbf{J}$ et al. Cerebral blood flow and quantitative rheoencephalography. Electroencephalogr. Clin. Neurophysiol. 1974;37:501-11.

18. Jacquy J, Charles P, Piraux A, Noel G. Relationship between the electroencephalogram and the rheoencephalogram in the normal young adult. Neuropsychobiol, 1980;6:341348 .

19. Markovich S, Scheinberg P, Shafey S, Namon R, Sano R. Clinical monopolar rheoencephalography. J. Neurol. Sci. 1967;5:267-72.

20. Seipel JH. The biophysical basis and clinical applications of rheoencephalography. Neurology. 1967;17:443-51.

21. Namon R, Gollan F, Shimojyo S, Sano RM, Markovich SE, Scheinberg P. Basic studies in rheoencephalography. Neurology. 1967; 17:239-52.
22. Lifshitz K. Rheoencephalography. I. Review of the technique. J. Nerv. Ment. Dis. 1963;136:388-98.

23. Lifshitz K. Rheoencephalography. II. Survey of clinical applications. J. Nerv. Ment. Dis. 1963;137:285-96.

24. Lehner H, Geyer N, Lugaresi E (eds). Rheoencephalography and plethysmographic methods. Excerpta, Amsterdam. 1969.

25. Yarullin HH. Clinical rheoencephalography. Medicina, Leningrad. 1967.

26. Geddes LA, Hoff HE, Hall CW, Millar HD. Rheoencephalography. Cardiovasc Res Cent Bull. 1964;44:112-22.

27. Polzer K, Schuhfried F. [Development and technic of rheography.] Wien Med Wochenschr. 1962;112:153-5. [Article in German]

28. Perez-Borja C, Meyer JS. A critical evaluation of rheoencephalography in control subjects and in proven cases of cerebrovascular disease. J. Neurol. Neurosurg. Psychiatr. 1964;27:66-72.

29. Markovich SE. International conference on bioelectrical impedance. Annals of the New York Academy of Sciences. 1970:170:407-837.

30. Eniya GI. Rheography as method of evaluation of cerebral blood flow (in Russian). Riga: Zinatne, 1973.

31. Naumenko AI, Skotnikov VV. Basics of Electroplethysmography (in Russian). Medicina, Leningrad. 1975.

32. Bodo M, Racz J, Ilias L, Pasztor A, Vajda J, Weinstein GB, Pasztor E, Moskalenko YE. Rheoencephalographic changes during increased intracranial pressure. In: Krieglstein J. editor. Pharmacology of Cerebral Ischemia. Amsterdam: Elsevier, 1986. pp 265-269.

33. Bodo M: Features of dynamics of rheoencephalographic parameters: experimental and clinical study. Ph.D. dissertation in Russian. Sechenov Institute of Physiology, Academy of Sciences of the USSR, St. Petersburg; Hungarian Academy of Sciences, Budapest, 1990.

34. Bodo M, Thuroczy G, Nagy I, Peredi J, Sipos K, Harcos P, Nagy Z, Voros J, Zoltai L, Ozsvald L: A complex cerebrovascular screening system. In: Lahtinen T. editor: Proceeding of the 8th International Conference on Electrical BioImpedance. July 28-31. Kuopio, Finland, 1992. pp 88-90.

35. Bodo M, Nagy I, Peredi J, Thuroczy G, Ozsvald L, inventors. Process and equipment for diagnosing circulation (cerebrovascular) disorders. Hungarian patent P 92011079. 1992 Mar 31; International patent PCT/HU 93/00006; PCT Pub. No: WO 93/19665. US patent, 5,584,297. 1996 Dec 17.

36. Bodo M, Thuroczy G, Nagy I, Peredi J, Sipos K, Harcos P, Nagy Z, Voros J, Zoltai L, Ozsvald L. A complex cerebrovascular screening system (Cerberus). Medical Progress through Technology 1995;21:53-66.

37. Kornhauser SH. Cerebrovascular diagnostic system. American Journal of Electromedicine, 1997 June: pp 69-71.

38. Bodo M, Thuroczy G, Brockbank K, Sipos K. Cerebrovascular aging assessment by Cerberus. In: Klatz R, Goldman R. editors Anti-aging medical therapeutics, vol. II. Health Quest, Marina Del Rey, CA, 1998;13:86-95. 
39. Sipos K, Bodo M, May Z, Lendvai B, Piros A, Spitzer N, Pataky I, Nagy Z, Banyasz A. Risk of mental disorders, their changes and somatic consideration in rural Hungary. Ideggyogy Sz, 2008;61:97-105.

40. Bodo M, Thuroczy G, Panczel G, Sipos K, Ilias L, Szonyi P, Bodo M Jr, Nebella T, Banyasz A, Nagy Z. Prevalence of stroke/cardiovascular risk factors in rural Hungary - a crosssectional descriptive study. Ideggyogy Sz, 2008;61:87-96.

41. Kabakcioglu M, Douligeris C, Bodo M, Thuroczy G. Application of machine learning and expert system methods for automated cerebrovascular screening. 2nd Hungarian Stroke Conference, Debrecen, Dec. 1-3. 1994, Poster \# 46.

42. Bodo M, Pearce FJ, Sowd M. In vitro and in vivo studies for a bio-impedance vital-sign monitor. Technical report; Defense Technical Information Center; DTIC\# ADA460555 Fort Belvoir, VA. 2006. http://www.dtic.mil/cgibin/GetTRDoc?AD $=$ ADA460555\&Location $=\mathrm{U} 2 \&$ doc $=$ Get TRDoc.pdf

43. Szalay P, Sipos K, Szucs L, Bodo M, Sowd M, Pearce FJ. REG can be used to detect cerebrovascular alteration caused by alcoholism. Acta Physiol Hung, 2006;93:117-130.

44. Szalay P, Bodo M, Sipos K, Szucs A. Correlation of anxiety and cerebrovascular disorder and the effect of physical activity in alcoholic patients. In: Hughes M, Dancs H, Nagyvradi K, editors: Research in sport science. Cardiff, UK, Data2Win, 2009. pp 209-221.

45. Thuróczy G, Kubinyi Gy, Sinay H, Bakos J, Sipos K, Lénárt Á. Szabó L.D. (1999): Human electrophysiological studies on influence of RF exposure emitted by GSM cellular phones. In: Bersani F. editor. Electricity and Magnetism in Biology and Medicine. Plenum Press, Oxford, pp 721-724.

46. Bodo M, Racz J, Moskalenko YE, Feher Z, Reiman K, Ilias $\mathrm{L}$ : Impedance and metabolic changes during increased intracranial pressure. 6th Int'l Conference on Bio-Impedance, Zadar (YU). In: Baturic P editor. Med. Jadertina, 1983; Suppl. 15: p 380.

47. Bodo M, Pearce FJ, Montgomery LD, Rosenthal M, Kubinyi G, Thuroczy G, Braisted J, Forcino D, Morrissette C, Nagy I. Measurement of brain electrical impedance: animal studies in rheoencephalography. Aviat Space Environ Med 2003;74:506-511.

48. Bodo M, Pearce FJ, Armonda RA. Cerebral blood flow changes: rat studies in rheoencephalography Physiol. Meas. 2004;25;1371-84

49. Thuroczy G, Kubinyi G, Bodo M, Bakos J, Szabo LD: Simultaneous response of brain electrical activity (EEG) and cerebral circulation (REG) to microwave exposure in rats. Reviews on Environmental Health, 1994;10:135-148.

50. Thuroczy G, Bodo M, Kubinyi G, Bakos J, Szabo LD. Rheoencephalogram and EEG activity increasing after microwave exposure on rats. In: Lahtinen T. editor. Proceeding of the 8th International Conference on Electrical BioImpedance. 1992 July 28-31. Kuopio, Finland, pp 92-94.

51. Thuroczy G, Szabo LD, Kubinyi G, Bakos J and Bodo M: Correlation between cerebral circulation and electrical activity (EEG) in the regulatory physiological mechanism of the central nervous system after microwave exposure of rats. In:
Blank M. editor. Electricity and Magnetism in Biology and Medicine, San Francisco Press, 1993. Pp 743-747.

52. Bodo M, Thuroczy G, Kubinyi G, Bakos J, Szabo LD: Slight polygraphic changes during microwave irradiation. VIIth Int'l Conf. on Bio-Impedance, Klagenfurt, A, 1987.

53. Bodo M, Pearce FJ, Baranyi L, Armonda RA. Changes in the intracranial rheoencephalogram at lower limit of cerebral blood flow autoregulation. Physiol Meas, 2005;26:S1-S17.

54. Bodo M, Szebeni J, Baranyi J, Savay S, Pearce FJ, Alving CR, Bünger R. Cerebrovascular involvement in liposome induced cardiopulmonary distress in pigs. J Liposome Res, 2005;15: 3-14.

55. Bodo M, Pearce F, Garcia A, Van Albert S, Settle T, Szebeni J, Baranyi L, Hartings J, Armonda R. In vivo cerebral blood flow autoregulation studies using rheoencephalography. International Conference on Electrical Bioimpedance, Apr. 4-8, 2010. Gainesville, FL. Journal of Physics: Conference Series. 2445.

56. Ahmed A, Bodo M, Van Albert S, Armonda RA. The effect of metal fragments on electrical monitoring: in vitro and in vivo studies. International Conference on Electrical Bioimpedance, Apr. 4-8, 2010. Gainesville, FL. Journal of Physics: Conference Series. 2443.

57. Bodo M, Garcia A, Pearce F, Van Albert S, Armonda R. Influence of volume and flow change on the electrical impedance signal (in vitro). International Conference on Electrical Bioimpedance, Apr. 4-8, 2010. Gainesville, FL. Journal of Physics: Conference Series. 2444.

58. Brady KM, Mytar JO, Kibler KK, Easley RB, Koehler RC, Czosnyka M, Smielewski P, Zweifel C, Bodo M, Pearce FJ, ArmondaRA. Monitoring cerebrovascular pressure reactivity with rheoencephalography. International Conference on Electrical Bioimpedance, Apr. 4-8, 2010. Gainesville, FL. Journal of Physics: Conference Series. 2446.

59. Anonymous. Exer-Rest at web site of NIMS: $\mathrm{http}: / / \mathrm{www}$. nims-inc.com/products.aspx? $\mathrm{t}=$ models

60. Hjorth B. The physical significance of time domain descriptors in EEG analysis. Electroencephalogr Clin Neurophysiol. 1973;34:321-5.

61. Pearce FJ, Bodo M, Armonda RA. Inventors: Method and Device for Brain Monitoring Using Rheoencephalography (REG) and Electroencephalograph (EEG). Docket No. WRAIR 09-28X. U.S. Provisional Patent Application Number $61 / 231,515,5$ August 2009.

62. Anonymous. Brain monitoring for neurosurgery and intensive care http://www.neurosurg.cam.ac.uk/icmplus

63. Czosnyka M, Smielewski P, Kirkpatrick P, Laing RJ, Menon D, Pickard JD. Continuous assessment of the cerebral vasomotor reactivity in head injury. Neurosurgery. 1997;41:11-7.

64. Anonymous. 10-20 system (EEG) http://en.wikipedia.org/ wiki/10-20_system_(EEG)

65. Heilig J, Thuroczy G, Bodo M, authors: Real time data display software: REDIREC. United States copyright, TXu 879 -647. 1998 June 17. 
66. Hanin, Y.L, Spielberger, C.D. The development and validation of the Russian Form of the State-Trait Anxiety Inventory. In: Spielberger CD \& Diaz-Guerrero R. (Eds). Crosscultural anxiety. Vol.2, Washington: Hemisphere Publishing Corporation, 1983 pp. 15-26.

67. Mancini GBJ. Angiographic assessment of atherosclerosis progression and regression. Woodford F.P, Davignon J, Sniderman A editors Atherosclerosis X. Amsterdam, NL: Elsevier; 1995. 984-988.

68. Fitch W. Physiology of the cerebral circulation Bailliere's Clinical Anaesthesiology 1999;13:487-498.

69. Chillon JM, Baumbach GL. Autoregulation: arterial and intracranial pressure. In: Cerebral Blood Flow and Metabolism. 2nd edition, IN: Edvinsson L, Krause DN. editors. Williams \& Wilkins, Philadelphia, PA, 2002 pp. 395-412.

70. Paulson OB, Strandgaard S, Edvinsson L. Cerebral autoregulation. Cerebrovasc Brain Metab Rev. 1990;2161-92.

71. Varon J. Diagnosis and management of labile blood pressure during acute cerebrovascular accidents and other hypertensive crises. Am J Emerg Med. 2007; 25:949-59.

72. Mendelow D, Crawford PJ, Primary and secondary brain injury. In: Reil PL, Bullock R. editors. Head injury. London; Arnold. 2005 pp73-92.

73. Czosnyika M, Hutchinson P, Kirkpatrick P J, Pickard J D. Monitoring of the Brain: Pressures, flows, and brain tissue probes. In: Jallo J, Loftus CM. editors. Neurotrauma and Critical Care of the Brain, Thieme, New York, 2009.

74. Perez JJ, Guijarro E, Barcia JA. Quantification of intracranial contribution to rheoencephalography by a numerical model of the head. Clin Neurophysiol. 2000;111:1306-14.

75. Perez JJ, Guijarro E, Barcia JA. Influence of the scalp thickness on the intracranial contribution to rheoencephalography. Phys Med Biol. 2004;49:4383-94.

76. Perez JJ, Guijarro E, Sancho J. Spatiotemporal pattern of the extracranial component of the rheoencephalographic signal. Physiol Meas. 2005;26:925-38.

77. Fabrizi L, Sparkes M, Horesh L, Perez-Juste Abascal JF, McEwan A, Bayford RH, Elwes R, Binnie CD, Holder DS. Factors limiting the application of electrical impedance tomography for identification of regional conductivity changes using scalp electrodes during epileptic seizures in humans. Physiol Meas. 2006;27:S163-74.

78. Manley G, Knudson MM, Morabito D, Damron S, Erickson V, Pitts L. Hypotension, hypoxia, and head injury: frequency, duration, and consequences. Arch Surg. 2001;136:111823.

79. Anonymous. Tactical Combat Casualty Care, Committee on Tactical Combat Casualty Care, Government Printing Agency, Washingon, DC. 2003.

80. Holcomb JB. Hypotensive resuscitation. (The resuscitation outline presented above summarizes the consensus of the Combat Fluid Resuscitation Conference 2001). http://www.drum.army.mil/sites/tenants/division/CMDGRP/ SURGEON/journals/HYPOTENSIVE\%20RESUSCITATIO N.htm
81. Rossignol R, Ebigwei-Ibru M. Drugs against hypoxia. Trends Pharmacol Sci. 1980; 1:287-289.

82. Pronk RA. Data processing for monitoring brain function during anesthesia and surgery. Electroencephalogr Clin Neurophysiol Suppl. 1987; 39:215-20.

83. Anonymous. Cushing reflex. http://en.wikipedia.org/wiki/ Cushing_reflex

84. Waschke KF, Riedel M, Lenz C, Albrecht DM, van Ackern $\mathrm{K}$, Kuschinsky W. Regional heterogeneity of cerebral blood flow response to graded pressure-controlled hemorrhage. J Trauma. 2004;56:591-603.

85. Kovach AG. Cerebral circulation in hypoxia and ischemia. Prog Clin Biol Res 1988;264:147-58.

86. Guyton AC. Textbook of medical physiology, 8th ed. Saunders, Philadelphia. 1991.

87. Bellamy R et al. Suspended animation for delayed resuscitation Crit. Care Med. 1996;24: S24-47.

88. Shoemaker W C et al. Resuscitation from severe hemorrhage Crit. Care Med. 1996;24: S12-23.

89. Aaslid R. Transcranial Doppler assessment of cerebral vasospasm. Eur. J. Ultrasound 2002;16:3-10.

90. Gur AY, Bornstein NM. TCD and the Diamox test for testing vasomotor reactivity: clinical significance. Neurol Neurochir Pol. 2001;35:3:51-6.

91. Madden JA. The effect of carbon dioxide on cerebral arteries. Pharmacol Ther 1993;59: 229-50.

92. Guyton A, Hall J. Textbook of medical physiology. $10^{\text {th }}$ ed. Philadelphia: WB Saunders Co., 2000. Figure 19-15.

93. Aidinis SJ, Lafferty J, Shapiro HM. Intracranial responses to PEEP. Anesthesiology. 1976;45:275-86.

94. Doblar DD, Santiago TV, Kahn AU, Edelman NH. The effect of positive end-expiratory pressure ventilation (PEEP) on cerebral blood flow and cerebrospinal fluid pressure in goats. Anesthesiology. 1981;55:244-50.

95. Drummond JC, Todd MM, Shapiro HM. The ICP/CBF effects of volume loading during PEEP administration. Anesthesiology. 1982;57:62-4.

96. Videtta W, Villarejo F, Cohen M, Domeniconi G, Santa Cruz R, Pinillos O, Rios F, Maskin B. Effects of positive end-expiratory pressure on intracranial pressure and cerebral perfusion pressure. Acta Neurochir Suppl. 2002;81:93-7.

97. Muench E, Bauhuf C, Roth H, Horn P, Phillips M, Marquetant N, Quintel M, Vajkoczy P. Effects of positive endexpiratory pressure on regional cerebral blood flow, intracranial pressure, and brain tissue oxygenation.. Crit Care Med. 2005;33:2367-72.

98. Caricato A, Conti G, Della Corte F, Mancino A, Santilli F, Sandroni C, Proietti R, Antonelli M. Effects of PEEP on the intracranial system of patients with head injury and subarachnoid hemorrhage: the role of respiratory system compliance. J Trauma. 2005;58:571-6.

99. Georgiadis D, Schwarz S, Baumgartner RW, Veltkamp R, Schwab S. Influence of positive end-expiratory pressure on 
intracranial pressure and cerebral perfusion pressure in patients with acute stroke. Stroke. 2001;32:2088-92.

100. Mausner JS, Kramer S. Mausner and Bahn Epidemiology An introductory text. Philadelphia, PA. WB Saunders Co. 1985. Pp 1-42.

101. Montgomery LD et al. An impedance device for study of multisegment hemodynamic changes during orthostatic stress. Aviat Space Environ Med 1989 ;60:1116-22.

102. Sokolova IV, Yarullin HH, Maksimenko IM, Ronkin MA. Analysis of the structure of rheoencephalogram as a pulse filling of blood (in Russian) J. Nevropathol 1977;77:13141321.

103. Sokolova IV, Iarullin KH. System of automatic analysis of rheoencephalograms. Kosm. Biol. Aviakosm. Med. 1982;16:81-3.

104. Vainshtein G B et al. Automated rheoencephalogram analysis Fiziol. Zh. SSSR Im. IM. Sechenova 1978;64:5647.

105. Kontos HA et al. Responses of cerebral arteries and arterioles to acute hypotension and hypertension. Am J Physiol. 1978;234:H371-83.

106. de Freitas GR, Bogousslavsky J. Primary stroke prevention. Eur J Neurol. 2001;81-15.

107. Wong KS, Ng PW, Tang A, Liu R, Yeung V, Tomlinson B. Prevalence of asymptomatic intracranial atherosclerosis in high-risk patients. Neurology, 2007;68:2035-8.

108. Laurent S, Boutouyrie P. Arterial stiffness and stroke in hypertension: therapeutic implications for stroke prevention. CNS Drugs. 2005;19:1-11.

109. Westerhof N, Lankhaar JW, Westerhof BE. The arterial Windkessel. Med Biol Eng Comput. 2009;47:131-41.

110. Olsson T, Broberg M, Pope KJ, Wallace A, Mackenzie L, Blomstrand F, Nilsson M, Willoughby JO. Cell swelling, seizures and spreading depression: an impedance study. Neuroscience. 2006;140:505-15.

111. Szebeni J, Baranyi L, Savay S, Lutz HU, Jelezarova E, Bunger R, Alving CR. The role of complement activation in hypersensitivity to pegylated liposomal doxorubicin (Doxil®). J. Liposome Res. 2000;10:467-481.

112. Armonda RA, Bell RS, Vo AH, Ling G, DeGraba TJ, Crandall B, Ecklund J, Campbell WW. Wartime traumatic cerebral vasospasm: recent review of combat casualties. Neurosurgery 2006;59:1215-1225.

113. Bell, Armonda et al, Military traumatic brain and spinal column injury: A 5-year study of the impact blast and other military grade weaponry on the central nervous system. J Trauma. 2009;66:S104-S111.

114. Hadjiev D, Yancheva S.Rheoencephalographic and psychological studies with ethyl apovincaminate in cerebral vascular insufficiency. Arzneimittelforschung. 1976;26:1947-50.

115. Solti F, Iskum M, Czako E. Effect of ethyl apovincaminate on the cerebral circulation. Studies in patients with obliterative cerebral arterial disease. Arzneimittelforschung 1976;26:1945-7.
116. Imamoto $\mathrm{T}$, Tanabe $\mathrm{M}$, Shimamoto $\mathrm{N}$, Kawazoe K, Hirata M. Cerebral circulatory and cardiac effects of vinpocetine and its metabolite, apovincaminic acid, in anesthetized dogs. Arzneimittelforschung. 1984;34:161-9.

117. Bönöczk P, Panczel G, Nagy Z. Vinpocetine increases cerebral blood flow and oxygenation in stroke patients: a near infrared spectroscopy and transcranial Doppler study. Eur J Ultrasound. 2002;15:85-91.

118. Nagy I, Bodo M, Thuroczy G, authors. GRAL: High-level interactive graphical language for signal processing. United States copyright TXu 1-025-933. 2001 April 9.

119. Wheatstone bridge. http://en.wikipedia.org/wiki/ Wheatstone_bridge

120. Cooper R, Osselton JW and Shaw JC. EEG Technology (London: Butterworth). 1980.

121. Gorelick PB. Stroke prevention. Arch. Neurol. 1995;52:34755 .

122. Perez-Borja C, Meyer JS. A critical evaluation of rheoencephalography in control subjects and in proven cases of cerebrovascular disease. J. Neurol. Neurosurg. Psychiat. 1964;27:66-72. 